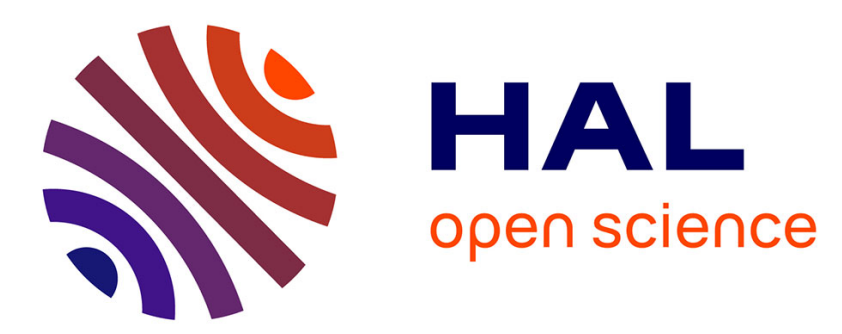

\title{
High-resolution backprojection at regional distance: Application to the Haiti M7.0 earthquake and comparisons with finite source studies,
}

\author{
L. Meng, J.-P. Ampuero, A. Sladen, H. Rendon
}

\section{- To cite this version:}

L. Meng, J.-P. Ampuero, A. Sladen, H. Rendon. High-resolution backprojection at regional distance: Application to the Haiti M7.0 earthquake and comparisons with finite source studies,. Journal of Geophysical Research, 2012, 117 (B04313), 10.1029/2011JB008702 . hal-00815468

\author{
HAL Id: hal-00815468 \\ https://hal.science/hal-00815468
}

Submitted on 2 Oct 2021

HAL is a multi-disciplinary open access archive for the deposit and dissemination of scientific research documents, whether they are published or not. The documents may come from teaching and research institutions in France or abroad, or from public or private research centers.
L'archive ouverte pluridisciplinaire HAL, est destinée au dépôt et à la diffusion de documents scientifiques de niveau recherche, publiés ou non, émanant des établissements d'enseignement et de recherche français ou étrangers, des laboratoires publics ou privés. 


\title{
High-resolution backprojection at regional distance: Application to the Haiti M7.0 earthquake and comparisons with finite source studies
}

\author{
L. Meng, ${ }^{1}$ J.-P. Ampuero, ${ }^{1}$ A. Sladen, ${ }^{2}$ and H. Rendon ${ }^{3}$ \\ Received 24 July 2011; revised 29 February 2012; accepted 1 March 2012; published 24 April 2012.
}

[1] A catastrophic $M_{w} 7$ earthquake ruptured on 12 January 2010 on a complex fault system near Port-au-Prince, Haiti. Offshore rupture is suggested by aftershock locations and marine geophysics studies, but its extent remains difficult to define using geodetic and teleseismic observations. Here we perform the multitaper multiple signal classification (MUSIC) analysis, a high-resolution array technique, at regional distance with recordings from the Venezuela National Seismic Network to resolve high-frequency (about $0.4 \mathrm{~Hz}$ ) aspects of the earthquake process. Our results indicate westward rupture with two subevents, roughly $35 \mathrm{~km}$ apart. In comparison, a lower-frequency finite source inversion with fault geometry based on new geologic and aftershock data shows two slip patches with centroids $21 \mathrm{~km}$ apart. Apparent source time functions from USArray further constrain the intersubevent time delay, implying a rupture speed of $3.3 \mathrm{~km} / \mathrm{s}$. The tips of the slip zones coincide with subevents imaged by backprojections. The different subevent locations found by backprojection and source inversion suggest spatial complementarity between high- and low-frequency source radiation consistent with high-frequency radiation originating from rupture arrest phases at the edges of main slip areas. The centroid moment tensor (CMT) solution and a geodetic-only inversion have similar moment, indicating most of the moment released is captured by geodetic observations and no additional rupture is required beyond where it is imaged in our preferred model. Our results demonstrate the contribution of backprojections of regional seismic array data for earthquakes down to $M \approx 7$, especially when incomplete coverage of seismic and geodetic data implies large uncertainties in source inversions.

Citation: Meng, L., J.-P. Ampuero, A. Sladen, and H. Rendon (2012), High-resolution backprojection at regional distance: Application to the Haiti M7.0 earthquake and comparisons with finite source studies, J. Geophys. Res., 117, B04313, doi:10.1029/ 2011JB008702.

\section{Introduction}

[2] The $M 7$ earthquake that hit Haiti in January 2010 was one of the most devastating natural disasters of the last decades. The disproportionate damage caused by this event and the prospect of future hazards in the region have prompted efforts to better understand its rupture process and the tectonics of the Northeast Caribbean, in particular the Enriquillo-Plantain-Garden fault (EPGF) and the surrounding fault systems. Nettles and Hjorleifsdottir [2010] found that a composite source model with a strike-slip subevent followed by a smaller thrust subevent was consistent with

\footnotetext{
${ }^{1}$ Seismological Laboratory, California Institute of Technology, Pasadena, California, USA.

${ }^{2}$ CNRS, Géoazur, University de Nice-Sophia Antipolis, Valbonne, France.

${ }^{3}$ Fundación Venezolana de Investigaciones Sismológicas, Caracas, Venezuela.

Copyright 2012 by the American Geophysical Union. 0148-0227/12/2011JB008702
}

long-period teleseismic data. Using geodetic data, Calais et al. [2010] and Hashimoto et al. [2011] attributed the slip to two asperities on a previously unmapped fault in the Leogane delta, north from the EPGF. Based on the analysis of geodetic, geologic and teleseismic observations, Hayes et al. [2010] also inferred rupture primarily on the blind Leogane fault, with a minor contribution on the EPGF. One possible uncertainty about this event is the extent of its rupture in the offshore areas where it cannot be directly constrained by onland geodetic data. In particular, this question became more of a concern after the identification of active offshore deformation by a marine geophysical survey and by the refined location of aftershocks derived from a combined temporary seismic network of 4 land and 21 ocean bottom stations (Haiti-OBS campaign) [Mercier de Lépinay et al., 2011].

[3] While finite fault inversions provide possible source models, they rely on a priori information about the fault geometry, which is not readily available for the Haiti event due to the geological complexity of the fault system and to the lack of surface rupture [Prentice et al., 2010] and strong 
motion recordings. In addition, the source inversion problem suffers from limited resolution of the spatiotemporal rupture process due to its low-frequency band. Source imaging by backprojection of body waves recorded by dense arrays allows us to track the areas of strongest high-frequency radiation [Ishii et al., 2005; Fletcher et al., 2006; Vallée et al., 2008]. This technique constrains the spatiotemporal properties of the rupture (length, direction, speed, segmentation) based solely on the phase of coherent seismic array signals. Thus, it does not rely on detailed knowledge of Green's functions and fault geometry, on restrictive parameterizations of the rupture kinematics, nor on additional smoothing. The high-frequency aspects of the rupture process imaged by array backprojection are complementary to traditional finite source inversion models based on teleseismic and geodetic data, which are instead sensitive to low frequencies and to the static field.

[4] Conventionally, backprojection is applied to large seismic arrays at teleseismic distances [Ishii et al., 2005; Meng et al., 2011] or to small aperture strong motion arrays at local distances [Spudich and Cranswick, 1984; Fletcher et al., 2006]. Seismic arrays at regional distances can provide higher aperture-to-distance ratio and thus higher resolution. Vallée et al. [2008] exploited surface waves recorded by a regional array to study the $2001 M_{w} 7.8$ Kunlun earthquake over a frequency band $(0.04$ to $0.1 \mathrm{~Hz})$ adequate to study very long ruptures, but too low to resolve smaller earthquakes. In principle, higher-frequency body waves carry higher-resolution information. However, the complexity of regional $P n$ waves has prevented seismologists from fully exploiting this phase for source imaging. Earthquake source studies using regional body wave phases have been mainly limited to inferring macroscopic source properties from recordings at distances up to a few hundred $\mathrm{km}$ [Zhu and Helmberger, 1996; Mendoza, 2005; Wei et al., 2009]. Guilbert et al. [2005] imaged the rupture propagation of a very large event, the $2004 M_{w} 9.0$ Sumatra earthquake, by array processing of body waves recorded by the CMAR seismic array at regional distance. Here, we further show that the relatively sustained character of the $P n$ phase enables the application of high-resolution array processing techniques on moderate earthquakes $(M \approx 7)$ to provide complementary constraints on rupture length and locations of high-frequency source radiation. This capability can contribute to rapid hazard and damage assessment for future earthquakes in the Caribbean region.

[5] The rest of this article is organized as follows. In section 2 we describe the data recorded by Venezuela National Seismic Network and argue for the need of high-resolution regional array analysis. In section 3 we present a high-resolution array source imaging technique adapted to earthquakes recorded at regional distance and quantify the resolution of the technique through extensive synthetic tests. In section 4 we present our results of source imaging of the Haiti earthquake by regional array analysis. In section 5 we integrate these results with independent analysis of apparent source time functions based on USArray data and an improved finite fault model based on teleseismic and geodetic data. In section 6 we discuss the rupture speed, the frequency-dependent source properties, the possibility of offshore coseismic rupture and the potential contribution of regional arrays to earthquake studies.

\section{VNSN Data, Preprocessing, and Selection}

[6] Our array backprojection study of the 2010 Haiti event is based on data recorded at regional distance by the Venezuela National Seismic Network (VNSN). The VNSN is composed of 22 broadband stations, oriented mainly eastwest, located approximately 9.5 degrees from Haiti in the perpendicular direction to the EPGF strike (Figure 1). The VNSN has a suitable geometrical configuration and location to study large earthquake ruptures in the Caribbean region.

[7] Array processing at regional distance aims at estimating the azimuth of arrival and relative timing of the seismic phases radiated from the strongest subevents of the earthquake. The study of the 2010 Haiti earthquake remains challenging because of its compact source size, shorter than $40 \mathrm{~km}$ according to previous studies [Calais et al., 2010; Hayes et al., 2010]. The resolution length scale along the fault that can be achieved with the standard beamforming techniques is evaluated by the array response function [Rost and Thomas, 2002]. Figure 2 shows the array response of the VNSN and the USArray, the nearest array at teleseismic distance. The array responses are backprojected into the hypocentral region of the 2010 Haiti earthquake based on $P$ travel times computed by the Tau-P toolkit and the IASP91 model [Snoke, 2009]. The array response of VNSN is not isotropic. It has low resolution along the range direction (the source-to-array direction) but adequate cross-range resolution (sub parallel to the fault strike in this case). In regional array processing, the range resolution is considerably poorer than the cross-range resolution, due to the small variability of the slowness of $P n$ waves as a function of epicentral distance. Hence, we compute the maximum of the array analysis result along lines parallel to the major axis of the array response pattern. Then these maxima are mapped onto the fault trace and plotted as a function of along strike position. The along-strike resolution length achieved by the USArray is approximately twice of that of the VNSN due to its more distant location and its more unfavorable orientation with respect to the fault strike. We note that the array response provides an ideal estimate of the array resolution. In practice, resolution is further affected by waveform incoherence and interference, as discussed through synthetic tests in section 3.2. Thus, to achieve adequate imaging of the Haiti earthquake the backprojection requires data from an array at regional distance. Moreover, since previous studies [Hayes et al., 2010; Calais et al., 2010] indicate that the rupture length of the Haiti earthquake is as compact as 40 $\mathrm{km}$, the analysis requires an array processing technique that can achieve higher resolution than standard beamforming.

[8] The Pn waveforms recorded by the VNSN are filtered between 0.2 and $0.7 \mathrm{~Hz}$. The low-frequency cutoff is dictated by a time-frequency trade-off (see section 3.1 ). The high-frequency cutoff is determined by the coherency of the array data, which is ultimately determined by the spacing between stations. The dominant frequency of the $P n$ waves is about $0.4 \mathrm{~Hz}$. We align the waveforms on their first arrival by multichannel alignment [Vandecar and Crosson, 1990] based on cross correlation of $10 \mathrm{~s}$ long windows containing 


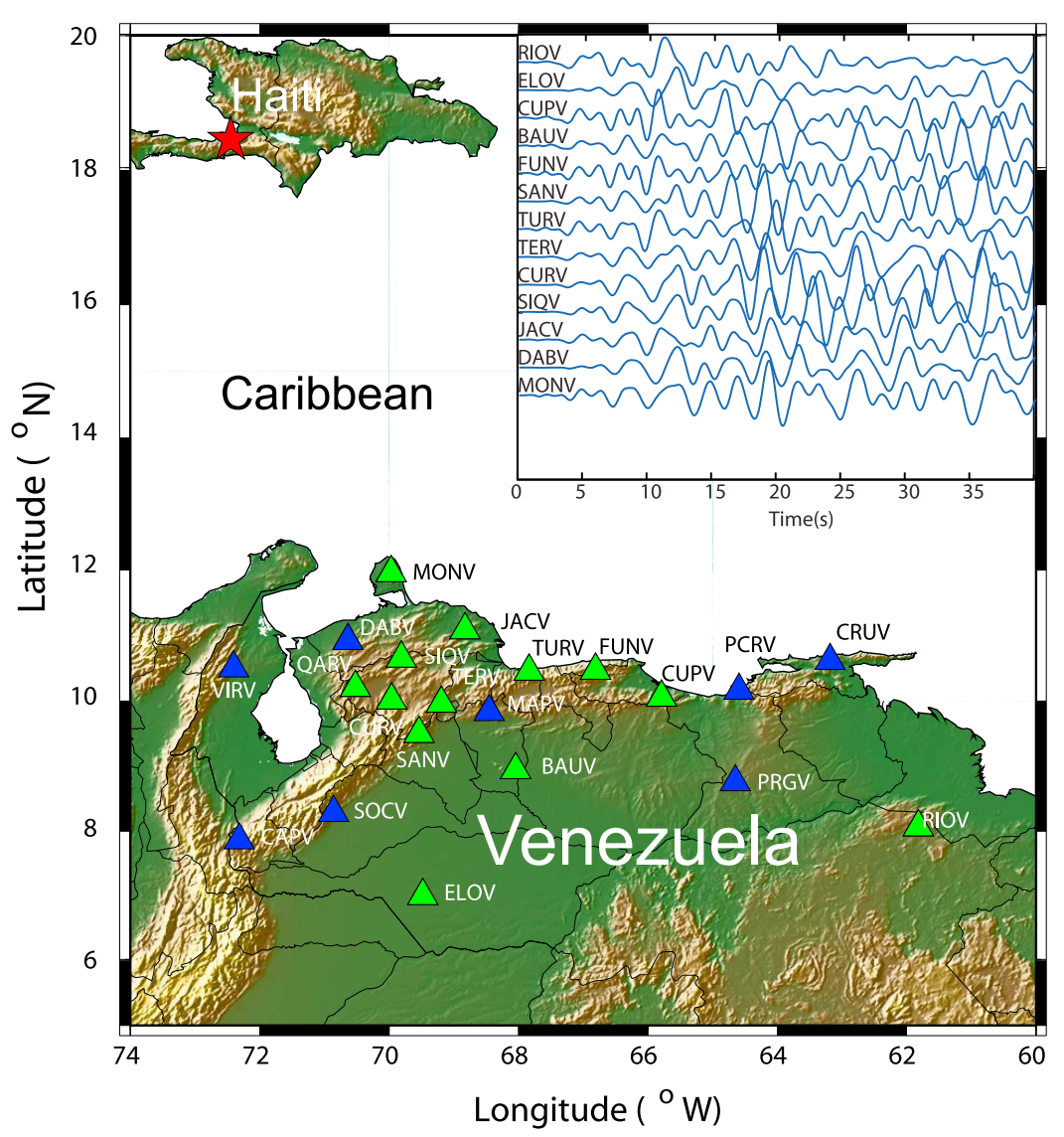

Figure 1. Haiti earthquake recorded by the Venezuela National Seismic Network (VNSN). The triangles denote the 22 broadband stations of the VNSN that recorded the 2010 Haiti earthquake. The 13 stations shown in green were selected for our analysis based on their mutual coherency and signal-to-noise ratio. The red star indicates the epicenter (NEIC) of the Haiti event. The inset shows vertical component seismograms filtered from 0.2 to $0.7 \mathrm{~Hz}$, aligned on their first $P$ arrival and normalized by the standard deviation of their first $10 \mathrm{~s}$.
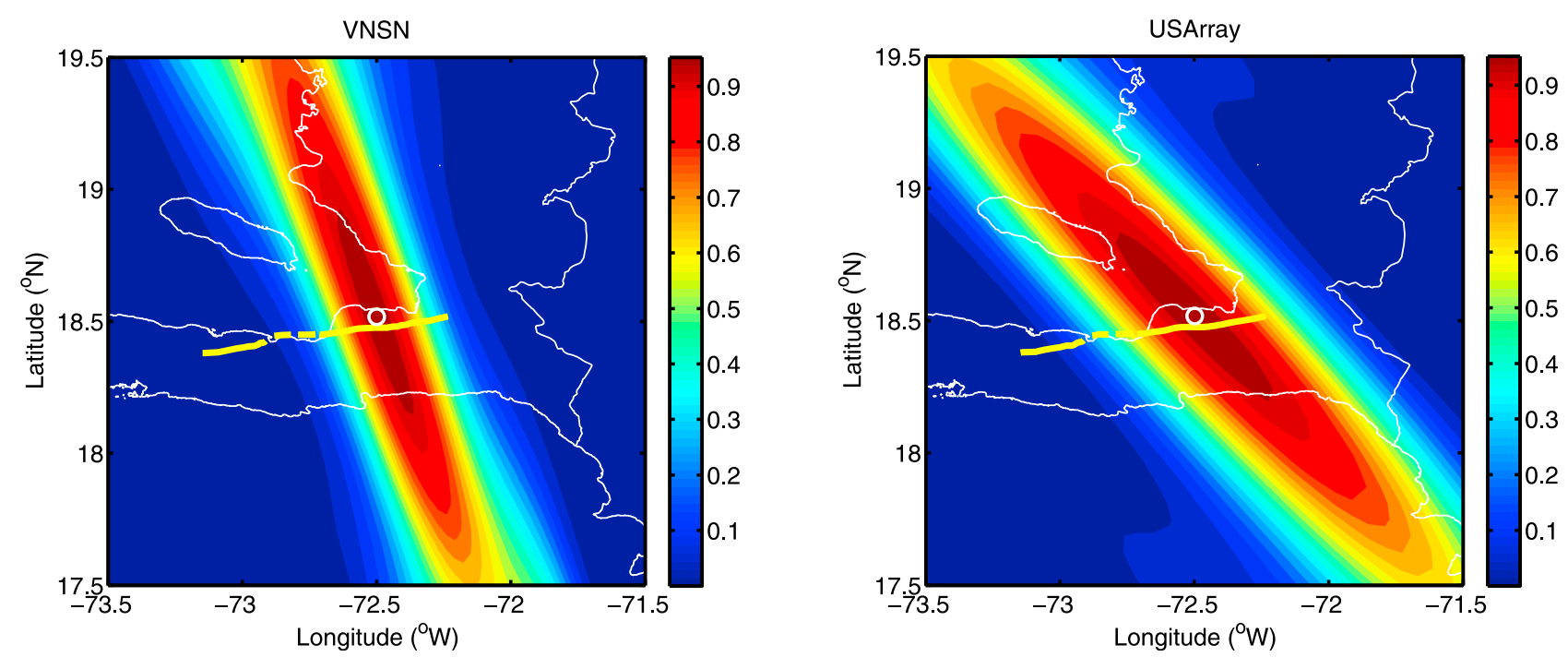

Figure 2. Array response patterns of the (left) VNSN and (right) USArray backprojected into the Haiti source region plotted in map view. The color scale indicates the power of the array response, normalized by its peak value. The yellow line denotes the trace of the EPGF [Calais et al., 2010]. The white circle is the location of the NEIC epicenter. 


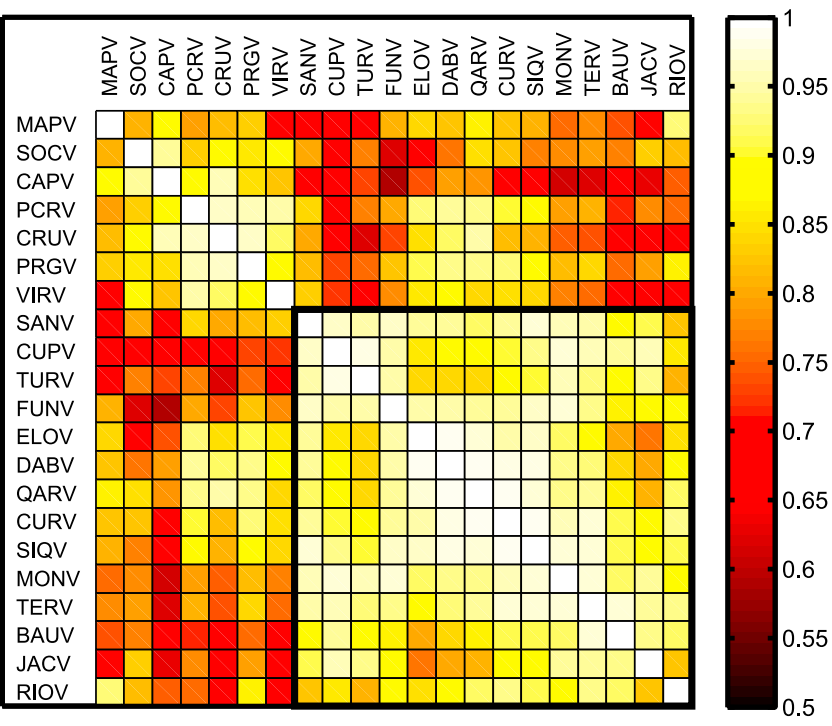

Figure 3. Station selection based on array data correlation matrix made of the correlation coefficients between all pairs of stations (indicated by the color scale). The stations are reordered by a clustering algorithm. The black box encompasses the most mutually coherent subset of stations, which is used in our array analysis.

the first $P n$ arrivals. This procedure reduces the effect of travel time errors due to uncertainties in the velocity structure [e.g., Ishii et al., 2005].

[9] Array processing techniques assume coherent signals across the array. We select a subset of 13 stations with adequate waveform coherency by inspecting the array data coherence matrix. This matrix is made of the coherence between all pairs of stations computed during the multichannel alignment procedure. The indices of the matrix are reordered to group together the most mutually coherent stations (Figure 3). We found a modified $\mathrm{k}$-nearest neighbors clustering algorithm (www.eigenvector.com/MATLAB/ Mac_Mfiles/corrmap.m) to be adequate for this purpose. After inspection of the reordered matrix we select a subset of 13 stations that consistently have correlation coefficients larger than 0.8 (Figure 3).

\section{High-Resolution Multitaper/MUSIC Technique for Regional Arrays}

\subsection{Outline of the Method and Parameter Settings}

[10] Here, we apply at regional distance a high-resolution array analysis technique originally developed for a teleseismic array study [Meng et al., 2011]. The method combines the multiple signal classification (MUSIC) array processing technique [Schmidt, 1986; Goldstein and Archuleta, 1991; Guilbert et al., 2005] with multitaper cross-spectrum estimation [Thomson, 1982]. MUSIC was designed for high-resolution direction of arrival estimation of long and stationary signals [Krim and Viberg, 1996]. The $P n$ phase is relatively stationary. The multitaper method yields a robust estimate of the data coherence matrix on relatively short time window and thus improves significantly the temporal resolution of MUSIC. Here we only describe the choice of processing parameters for this particular study.
More details about the method are described by Meng et al. [2011].

3.1.1. Number of Tapers in Cross-Spectrum Estimation

[11] The multitaper technique [Thomson, 1982] averages multiple, almost independent cross-spectral estimates obtained after tapering the data by a sequence of orthogonal functions with optimal temporal and spectral concentration. These Slepian tapers are the set of functions of finite temporal duration $\mathrm{T}$ with maximum energy within the band of frequencies lower than the bandwidth $\mathrm{W}$. Given a time window duration $\mathrm{T}$ and a frequency bandwidth $\mathrm{W}$, the proper number of tapers is $2 \times \mathrm{T} \times \mathrm{W}-1$. As a compromise between useful averaging (large $\mathrm{T} \times \mathrm{W}$ ) and adequate temporal resolution (short T) we use here 3 tapers, which implies $\mathrm{T} \times \mathrm{W}=2$.

\subsubsection{Length of Analysis Window}

[12] The MUSIC method requires narrow band estimates of cross spectrum, i.e., the bandwidth $\mathrm{W}$ (the frequency smearing of the spectral estimator) has to be small compared to any frequency of analysis, $\mathrm{W} \ll \mathrm{f}$. This implies a trade-off between temporal resolution and frequency localization: $\mathrm{T} \times$ $\mathrm{f} \gg 2$ for 3 tapers. As a compromise here we set $\mathrm{T}=30 \mathrm{~s}$, which satisfies $\mathrm{T} \times \mathrm{f}>6$ for frequencies higher than $0.2 \mathrm{~Hz}$. At the dominant frequency of our data, $\mathrm{f} \approx 0.4 \mathrm{~Hz}$, we get $\mathrm{T} \times \mathrm{f} \approx 12$.

\subsubsection{Number of Principal Eigenvalues}

[13] In MUSIC the signal subspace is defined as the subspace spanned by the distinctly largest eigenvalues of the data covariance matrix. Its complement defines the noise subspace. For stationary signals, the dimension $\mathrm{N}$ of the signal subspace is equal to the number of signal sources contributing to the data time window. In the case of transient seismic signals analyzed with relatively short time windows, each covariance matrix estimated with a separate taper tends to have only one nonzero eigenvalue and the associated eigenvectors tend to be independent. Hence, the rank of the covariance matrix obtained by linear combination of the multiple taper estimates tends to be equal to the number of tapers. In particular, the number of significant eigenvalues is at most three when using three tapers. Figure 4 shows results of the MUSIC analysis of the 2010 Haiti earthquake at $0.4 \mathrm{~Hz}$, the dominant frequency of the seismograms, with $\mathrm{N}$ ranging from 1 to 4 . The MUSIC pseudospectrum, a measure of the orthogonality between the array steering vector associated to a candidate source location and the noise subspace (for details, see Meng et al. [2011]), is plotted as a function of along-strike position with respect to the hypocenter and as a function of end time of the sliding windows. The MUSIC pseudospectrum is normalized by its maximum in each time window. Its amplitude depends on signal power, coherence and interference but it does not directly represent any physical quantity. Nevertheless, the sharp peaks of the MUSIC pseudospectrum indicate the location of signal sources. In the MUSIC analysis of the Haiti earthquake, two main subevents (black dots in Figure 4b) are visible and their estimated locations are independent of the choice of $\mathrm{N}$. However, when $\mathrm{N}$ is too small $(\mathrm{N}=1)$ the analysis fails to resolve two simultaneous sources. It only indicates the strongest source in each time window. The results with $\mathrm{N}=2$ or 3 show stable features of the rupture process including simultaneous multiple sources. When $\mathrm{N}$ is larger than the number of nonzero eigenvalues 

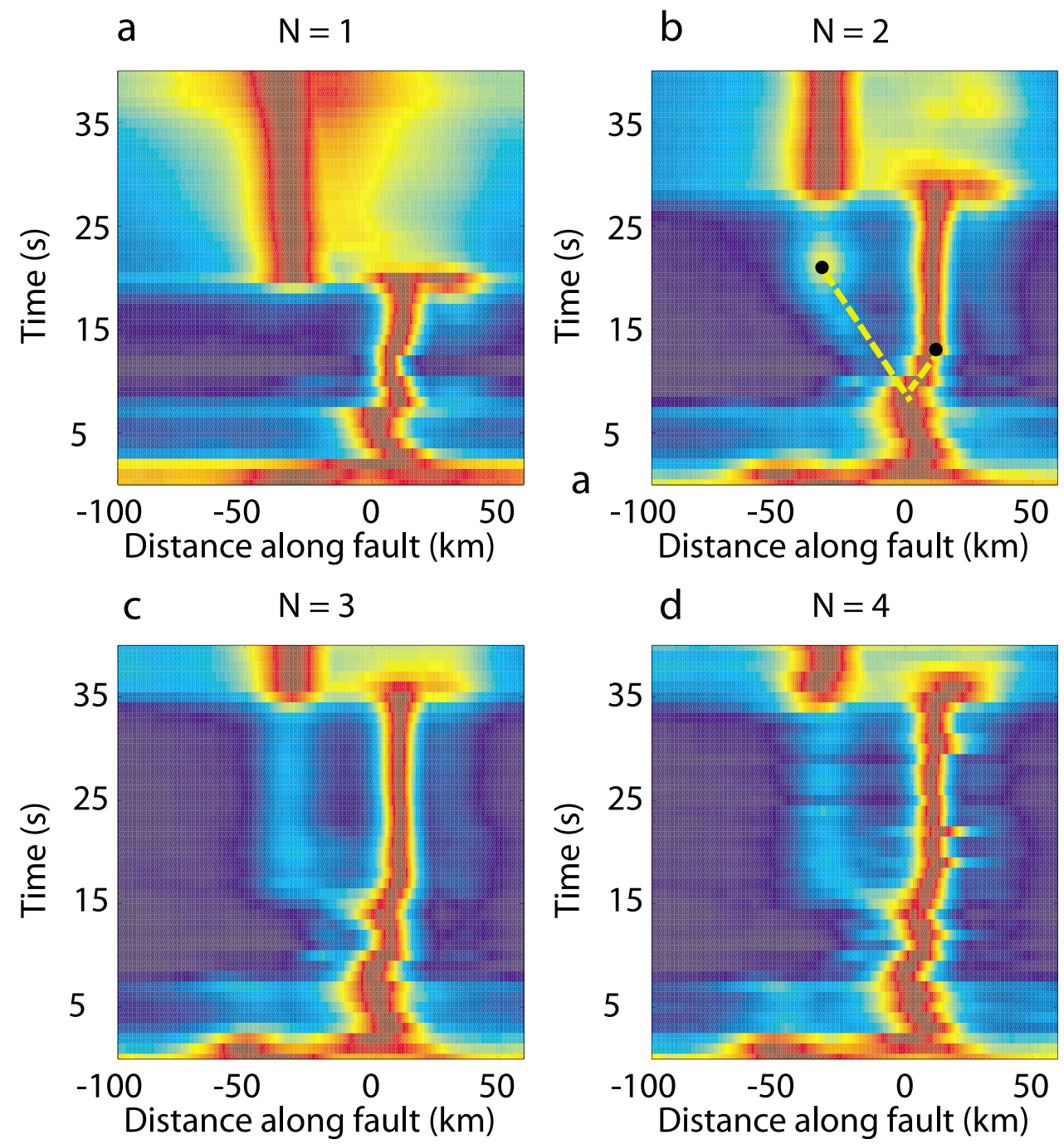

Figure 4. Dependence of MUSIC results on the assumed size $\mathrm{N}$ of the signal subspace at $0.4 \mathrm{~Hz}$ with $\mathrm{N}=$ (a) 1, (b) 2, (c) 3, and (d) 4. The MUSIC pseudospectrum as a function of along-strike position with respect to the hypocenter is shown in color and normalized by its maximum in each time window. The time axis is defined as the final time of the sliding windows of $30 \mathrm{~s}$ long sliding windows. The horizontal axis is the distance along the fault with respect to the epicenter. The yellow dashed lines and the black dots in Figure $4 \mathrm{~b}$ show the bilateral rupture trend and subevent locations.

(e.g., $\mathrm{N}=4$ ), the signal subspace is contaminated by noise and the resulting image is not stable. While the spatial location of the subevents is independent of the choice of $\mathrm{N}$, their estimated timing is not. Because we have not developed yet a complete understanding of the effect of $\mathrm{N}$ on the timing of subevents, an objective rationale for the choice of $\mathrm{N}$ is not available at this time. Here we choose $\mathrm{N}=2$ because it yields the most clear image of the westward rupture front and the resulting rupture speed is within the usual range, consistent with independent observations available for this earthquake, as described in later sections. We note, however, that the temporal details of the backprojection images, which depend on $\mathrm{N}$, are not used as additional constraints to infer the rupture speed of this earthquake. Because of the normalization, the MUSIC pseudospectrum in Figure 4 persists for a long time and reflects the sustained $P n$ phase rather than the source duration.

\subsection{Resolution Tests}

\subsubsection{Synthetic Test for an Ideally Coherent Linear} Array

[14] Figure 5 compares the resolution of four techniques on synthetic transient signals: MUSIC, beamforming, cubic root stacking (a popular modification of beamforming [e.g., Rost and Thomas, 2002]), and correlation stacking. In correlation stacking the normalized cross-correlation coefficients are beamformed instead of the waveforms [Fletcher et al., 2006] to improve robustness against scattering, multipathing and contamination by coda waves [Borcea et al., 2005]. The color scale in the images by correlation stacking and cubic root stacking indicate beamformed crosscorrelation coefficients and beamformed cubic root of the signal amplitude, respectively, evaluated or integrated over a sliding time window of duration $30 \mathrm{~s}$. The resolution of a method is defined as its ability to separate closely spaced 

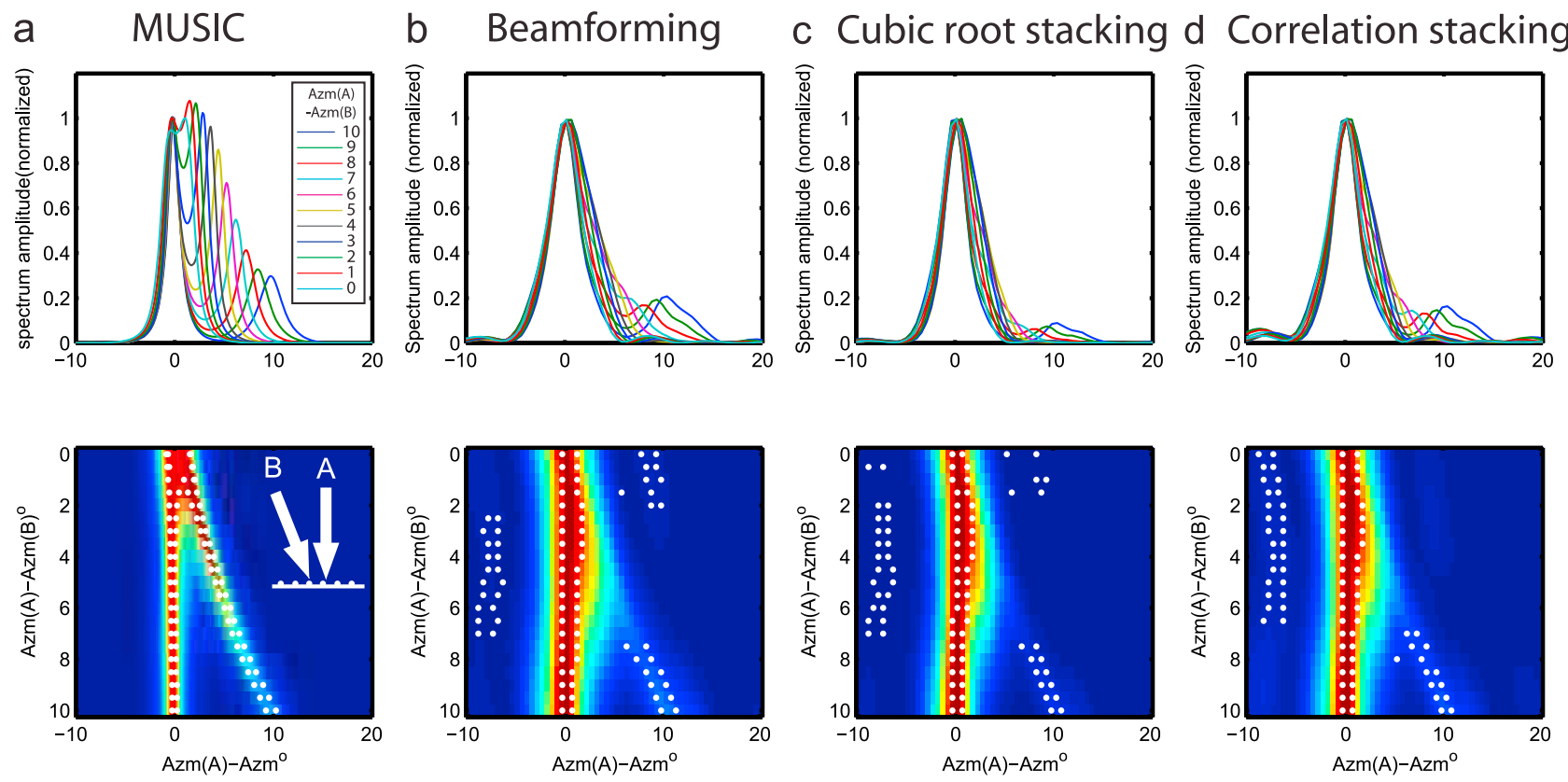

Figure 5. Comparison of resolution between array processing techniques. Two plane waves, A and B, impinge on a linear array. The azimuth of $\mathrm{A}$ is fixed at 0 degrees while the azimuth of $\mathrm{B}$ is varied from -10 to 0 degrees. Four array processing techniques are considered: (a) MUSIC, (b) classical beamforming, (c) cubic root stacking, and (d) correlation stacking. Each curve in the top plots shows either pseudospectra (Figure 5a) or the stack (Figures $5 \mathrm{~b}-5 \mathrm{~d}$ ) as a function of relative azimuth with respect to A for a given azimuth separation between $\mathrm{A}$ and $\mathrm{B}$ (value indicated in the legend). The bottom shows the same quantities in color plots (color scale indicated in Figure 2). The white dots mark the half width of the two largest maxima at a given azimuth of B. This comparison shows that MUSIC can resolve waves with azimuth separation as small as 3 degrees, achieving at least twice higher resolution (minimum resolvable azimuthal separation) than the other methods.

sources. We consider two identical $P n$ plane waves with dominant frequency of $0.3 \mathrm{~Hz}$ impinging simultaneously but with different azimuth on a linear array of 21 sensors regularly spaced at half wavelength. Gaussian white noise is added with a signal-to-noise ratio of $10 \mathrm{~dB}$. The results as a function of the relative azimuth between the two waves (Figure 5) show that, the minimum azimuthal separation resolvable by MUSIC, beamforming, cubic root stacking, correlation stacking and is approximately $3,8,8$, and 8 degrees, respectively. This shows that, under perfect waveform coherency, the azimuthal resolution, and hence the spatial resolution in the cross-range direction, achieved by our multitaper MUSIC method achieves azimuthal resolution that outperforms the other methods by at least a factor of two.

\subsubsection{Synthetic Test for the VNSN Array Geometry}

[15] Figure 6 shows further synthetic tests to understand the performance and potential bias of the backprojection of the Haiti earthquake source using the VNSN data. We compute full wavefield synthetics (Figure S1 in the auxiliary material) using the SPECFEM3D package [Tromp et al., 2008 ] with the $3 \mathrm{D}$ crustal velocity model Crust 2.0 [Bassin et al., 2000]. ${ }^{1}$ Our simulations are accurate up to $0.33 \mathrm{~Hz}$. Given the uncertainties in the velocity model, generating higher frequency synthetics is not warranted. Inspired by the

${ }^{1}$ Auxiliary materials are available in the HTML. doi:10.1029/ 2011JB008702. final result of the backprojection, we test scenarios with a source containing two asperities. The first one is located at the hypocenter of the Haiti earthquake. The second one is located westward along the hypothetical Leogane fault trace [Hayes et al., 2010]. We consider either the same slip amplitude for both subevents or a 2:1 ratio based on the source time functions estimated at the USArray (see section 5.1). We explore intersubevent distances up to $50 \mathrm{~km}$, with rupture time delays consistent with a rupture speed of $3 \mathrm{~km} / \mathrm{s}$. For both asperities we assume source parameters from the CMT solution (focal mechanism 251/ 70/28, strike/dip/rake, and centroid depth $12 \mathrm{~km}$ ) and a Brune source time function with duration of $3 \mathrm{~s}$. In Figure 6 , the left two columns show examples of cubic root stacking, correlation stacking and MUSIC pseudospectra. These quantities are backprojected onto the source area based on $P$ travel times computed by the Tau-P toolkit and the IASP91 model [Snoke, 2009].

[16] We found that all the backprojection methods are modulated by interference between subevents. This introduces an amplitude and location fluctuation that depends periodically on the product of intersubevent time delay and frequency of analysis. At some distance, the second subevent is recovered well, but not at some other distances, depicted as multiple horizontal bars in right two columns of Figure 6. Figure 7 shows two examples of interference in the cubic root stacking analysis at $0.3 \mathrm{~Hz}$ with sources separated by 15 and $40 \mathrm{~km}$. The time delay between the wave arrivals 


\section{a Cubic root stacking}
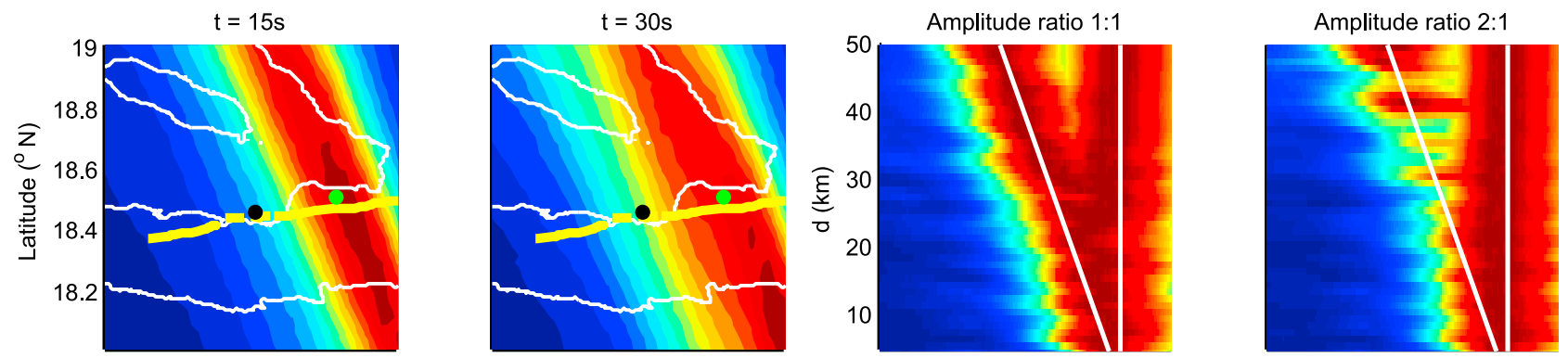

\section{b Correlation stacking}
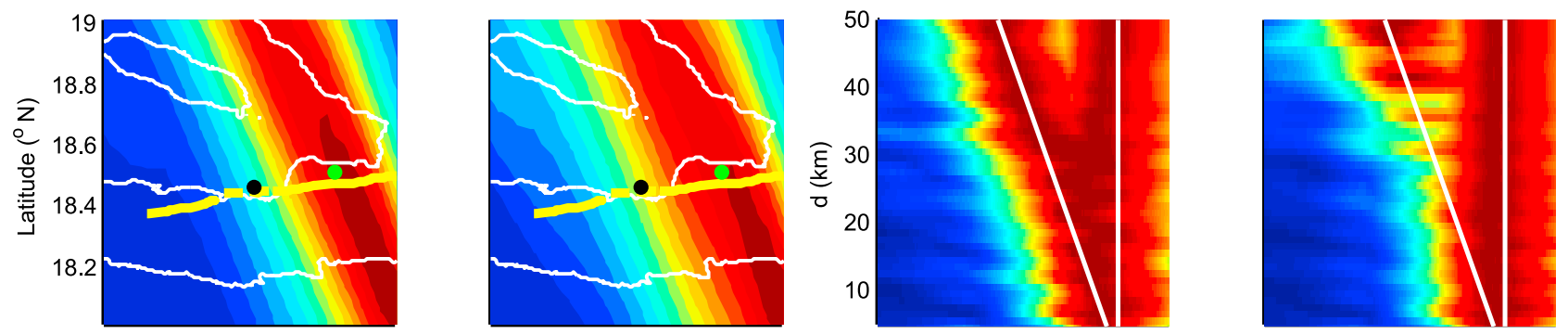

\section{c MUSIC}
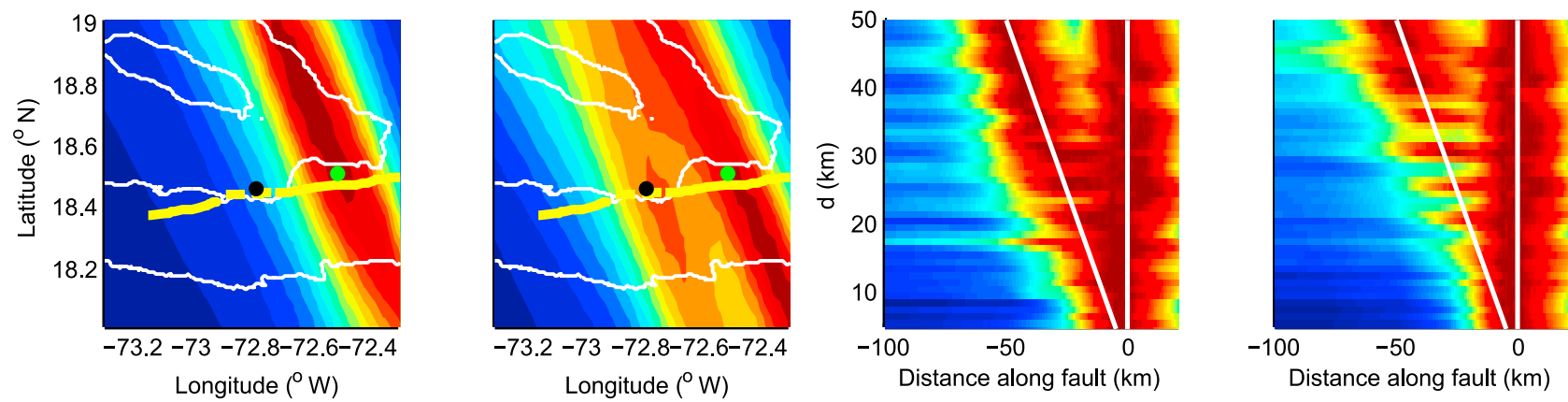

Figure 6. Synthetic test of array processing for the Haiti earthquake scenario. The earthquake is modeled by two point sources with $3 \mathrm{~s}$ long Brune source time functions. The first source is at the hypocenter (green dot), and the second one is at a distance $d$ (black dot) westward along the fault trace. We applied (a) cubic root stacking, (b) correlation stacking, and (c) MUSIC. The left two columns are map view backprojection images for $\mathrm{d}=30 \mathrm{~km}(10 \mathrm{~s}$ delay), in the time windows ( $30 \mathrm{~s}$ long) that end at $\mathrm{t}=15 \mathrm{~s}$ and $\mathrm{t}=30 \mathrm{~s}(\mathrm{t}=0$ is arrival time of the first source). The right two columns show the projection of the images along the sourceto-array direction onto the fault trace as a function of the distance $d$. The white lines indicate the locations of the two sources. We considered moment ratios between first and second sources of 1:1 and 2:1. In the case of 2:1 source ratio, the cubic root stacking and correlation stacking methods show resolution limit of about $35 \mathrm{~km}$, while the resolution limit of MUSIC is about $25 \mathrm{~km}$ and the location error is approximately $5 \mathrm{~km}$ for each subevent.

from the two asperities varies across the array. Destructive interference occurs at stations where the waves from the two asperities are out of phase with respect to the dominant period (the seismograms of some stations are deficient in low frequencies in Figure 7). This interference results in incorrect imaging of two sources (left columns in Figure 7). This issue might be less severe in practice, since the synthetics are computed from two point sources. In reality, the broader slip region reduces the simultaneous destructive interference.
[17] As expected from the resolution test, MUSIC achieves a smaller resolvable distance than the other two techniques. This difference is particularly prominent when we set a more realistic 2:1 amplitude ratio for the two sources. The left two columns in Figure 6 show the two snapshots taken at $30 \mathrm{~s}$ long time windows ending at $\mathrm{t}=15 \mathrm{~s}$ and $\mathrm{t}=30 \mathrm{~s}$ when $\mathrm{d}=30 \mathrm{~km}$. At $\mathrm{t}=30 \mathrm{~s}$, the window includes the simultaneous signals from both events. While the MUSIC pseudospectrum clearly gives two peaks in the second snapshot, the other two techniques fail to resolve 
Two sources $15 \mathrm{~km}$ apart

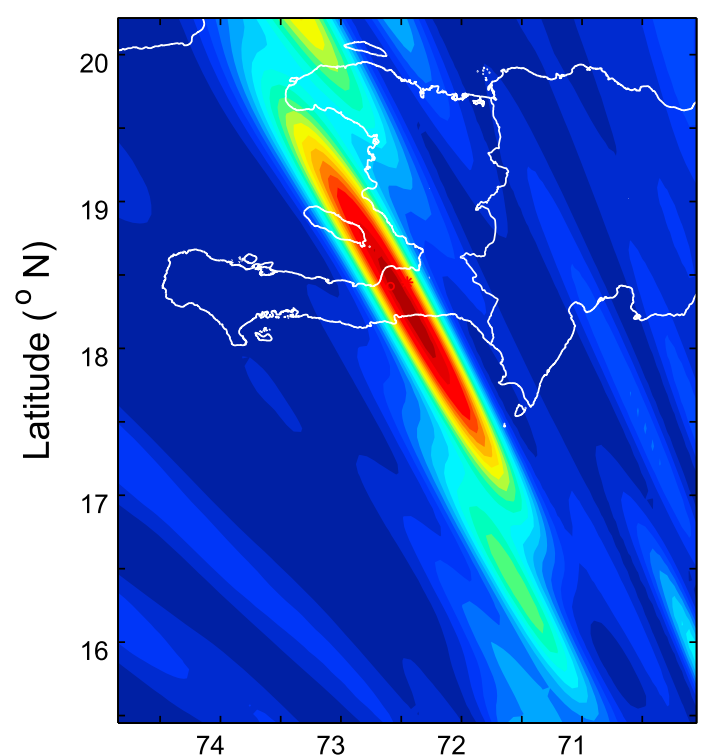

Longitude $\left({ }^{\circ} \mathrm{W}\right)$

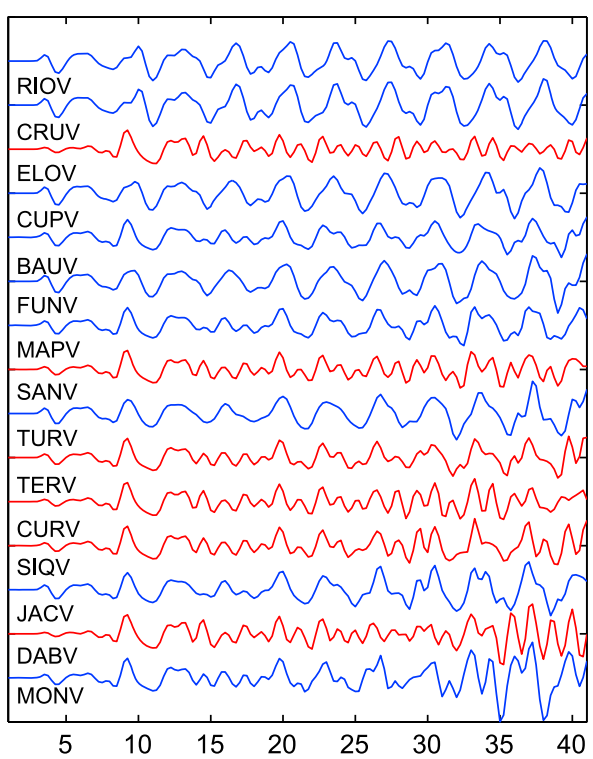

Time (s)

Two sources $30 \mathrm{~km}$ apart
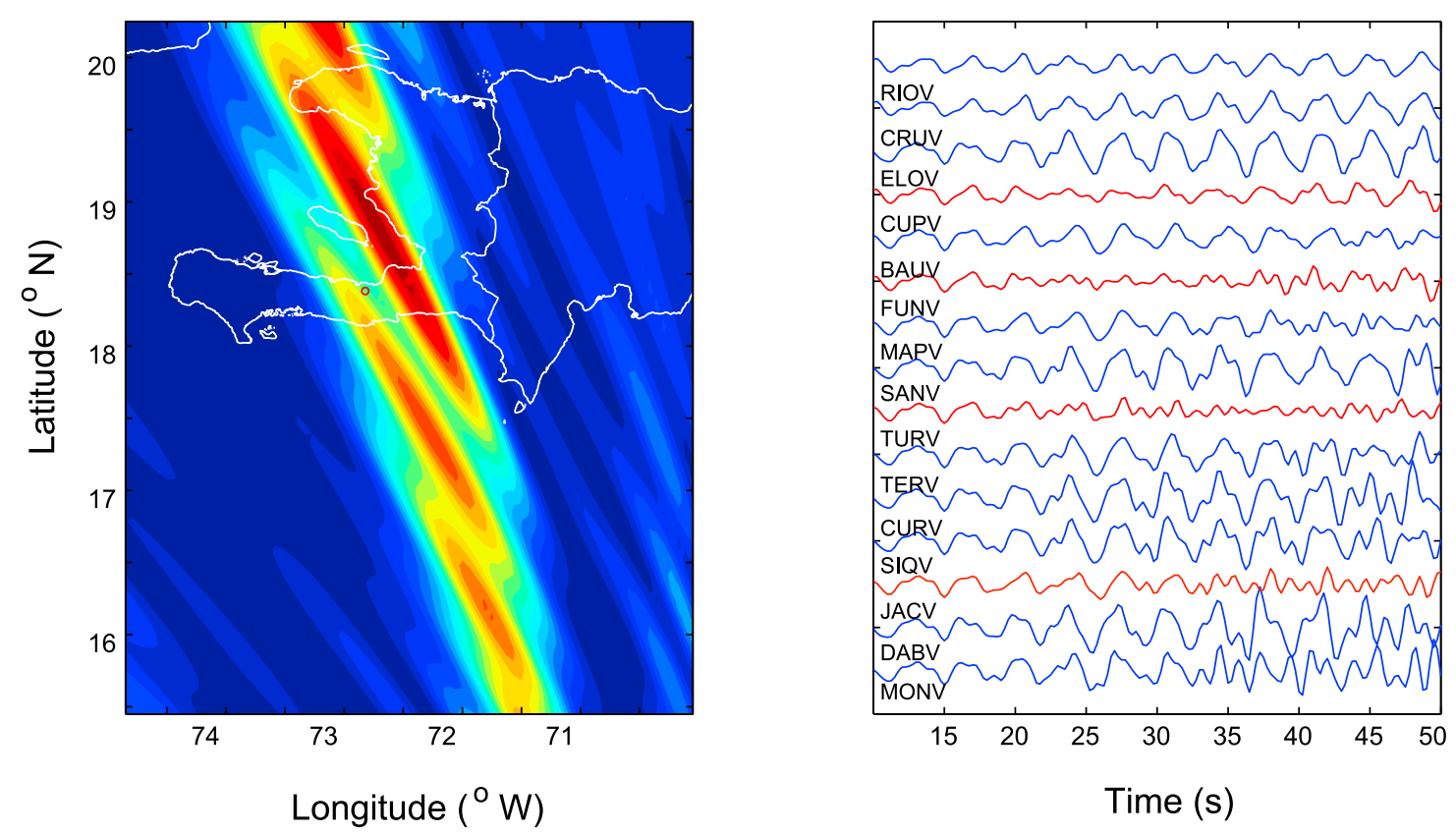

Figure 7. Interference issues associated with the beamforming analysis. Results of two synthetic tests with a composite source comprising two subevents: (top) $15 \mathrm{~km}$ and (bottom) $30 \mathrm{~km}$ apart with Green's function computed with the frequency-wave number method of Zhu and Rivera [2002]. The $30 \mathrm{~s}$ long time window ends at $15 \mathrm{~s}$ after the arrival of the second source. On the left are maps of cubic root beam amplitude backprojected into the source region. On the right are synthetic seismograms. The stations deficient in low frequencies due to interference effects are colored in red.

them. Note that the absolute amplitude of the MUSIC pseudospectrum, which is modulated by interference patterns, does not directly represent the signal power and is not used in the analysis. The resolution limit for MUSIC in these synthetic tests is approximately $25 \mathrm{~km}$ (the distance beyond which we can separate two sources) with an uncertainty of about $5 \mathrm{~km}$ for each subsource. Because the interference effect is less prominent in actual data since they are generated by distributed sources instead of point sources, we 

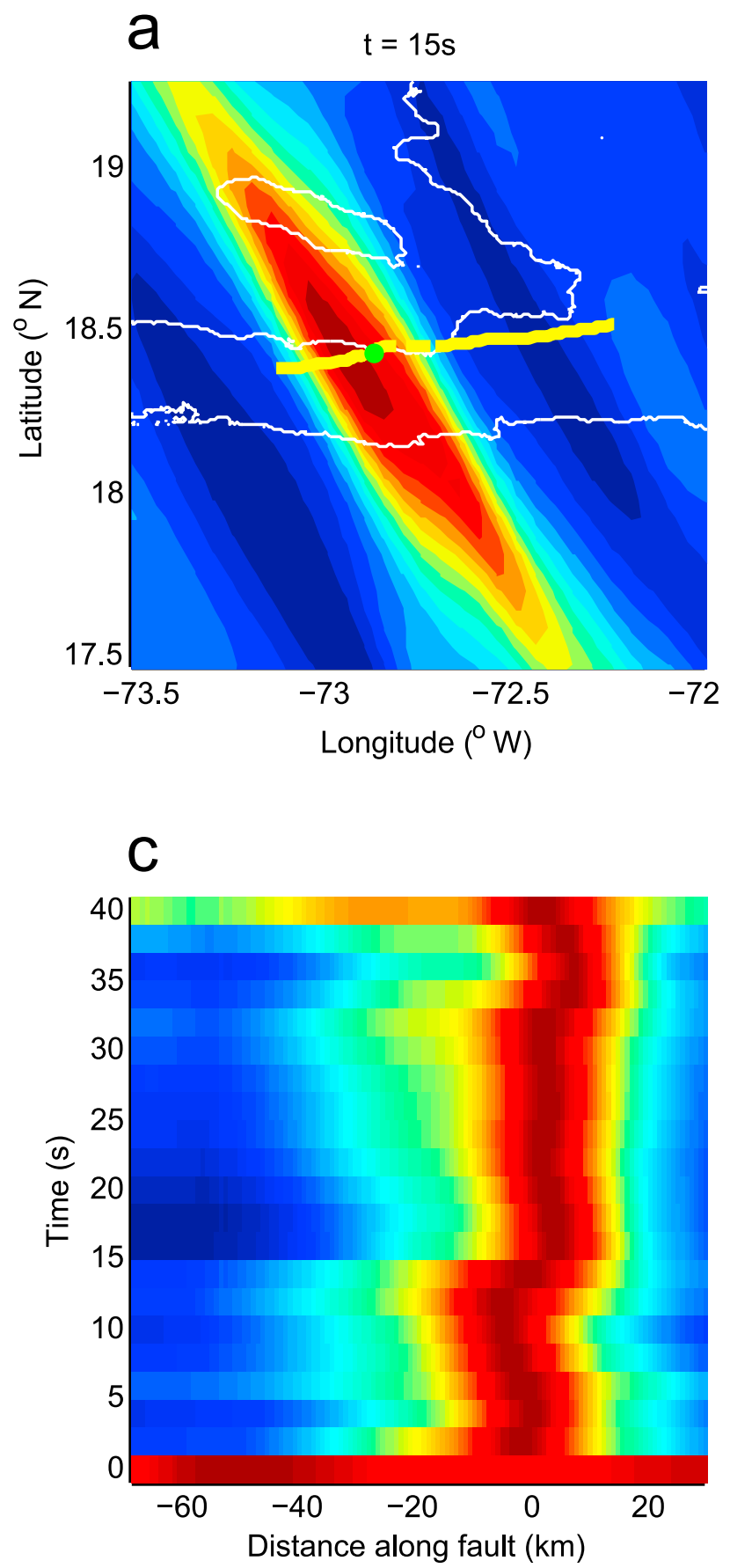

b $\quad t=30 s$

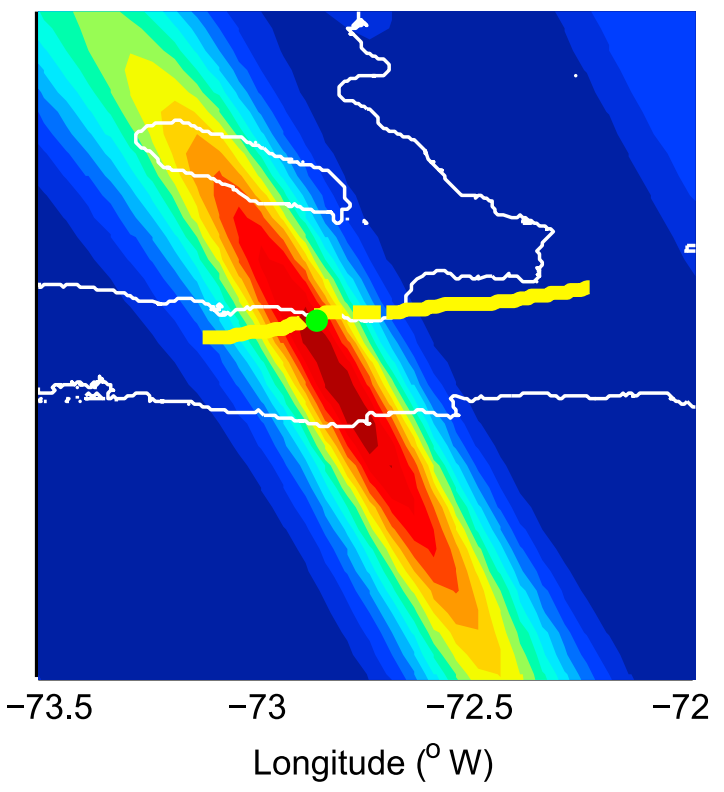

d

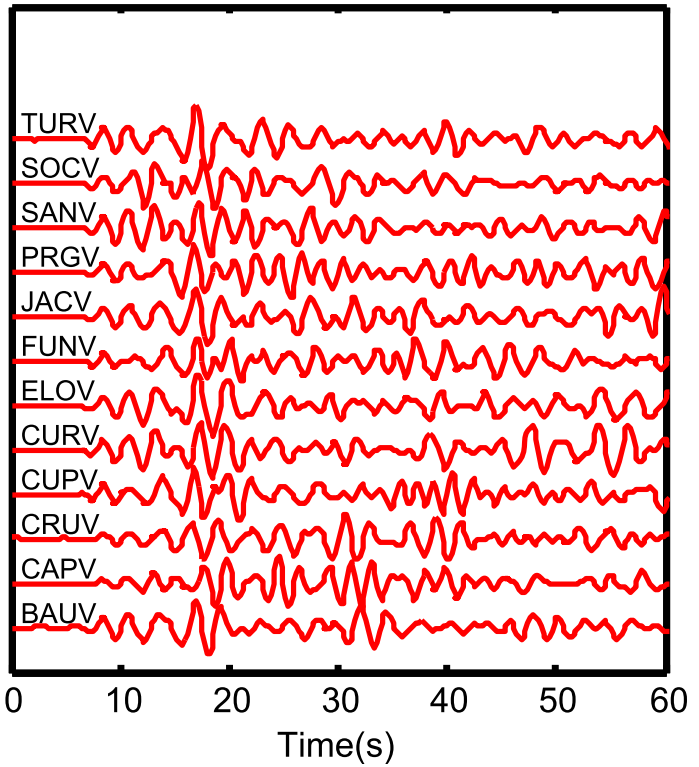

Figure 8. The MUSIC analysis of the largest aftershock (M5.9). (a and b) MUSIC images from $30 \mathrm{~s}$ long time windows ending at $\mathrm{t}=15 \mathrm{~s}$ and $30 \mathrm{~s}(\mathrm{t}=0 \mathrm{~s}$ is the arrival time). The green dot indicates the location of the epicenter. The yellow curve indicates the trace of the EPGF [Calais et al., 2010]. (c) The projection on the fault as a function of final time of the sliding window. (d) The vertical recordings of the aftershock recorded at the VNSN filtered at $0.2 \sim 0.7 \mathrm{~Hz}$.

consider $25 \mathrm{~km}$ and $5 \mathrm{~km}$ are safe estimates of the resolution limit and the relative location uncertainty in our analysis.

\section{Results of Array Analysis of the 2010 Haiti Earthquake at Regional Distance}

[18] We first illustrate the accuracy of our method by an analysis of the largest aftershock, a M5.9 (NEIC) earthquake on 20 January 2010 (waveform shown in Figure 8). The backprojection of the MUSIC pseudospectrum into the source region is shown in map view in Figures $8 \mathrm{a}$ and $8 \mathrm{~b}$ for two windows ending at $\mathrm{t}=15 \mathrm{~s}$ and $30 \mathrm{~s}$ after the first arrival, respectively. The warmest color indicates the location of the source of the waves arriving at the VNSN within these time windows. As explained in section 2, the backprojected contours are very elongated in the source-to-array 


\section{a Cubic root stacking}

$t=15 s$
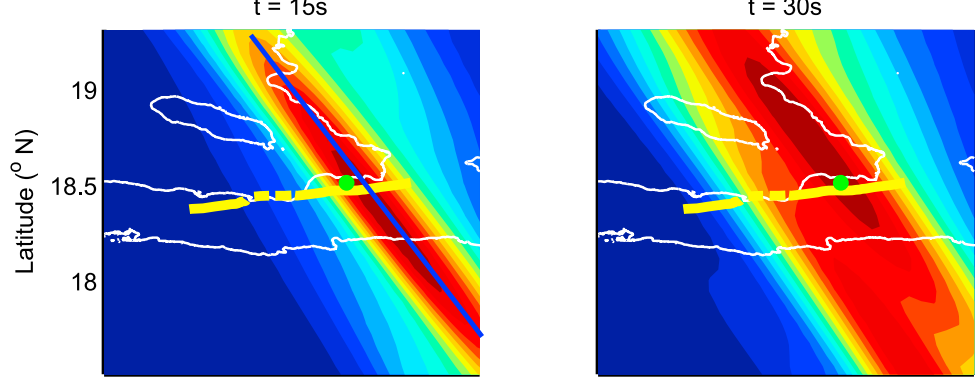

b Correlation stacking
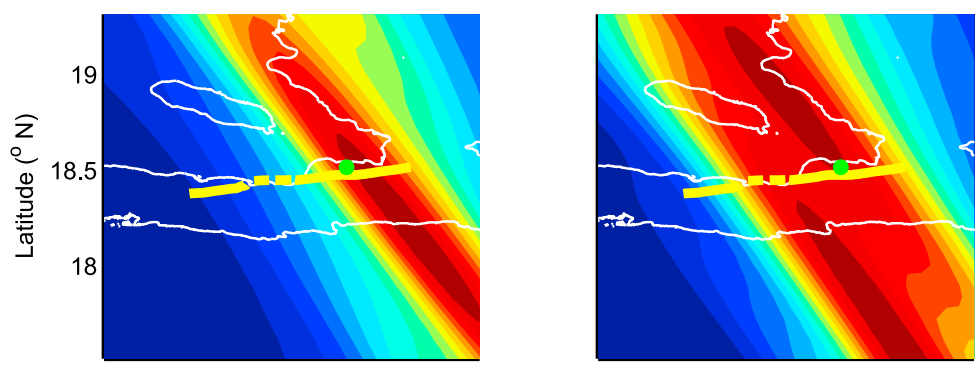

\section{c MUSIC}

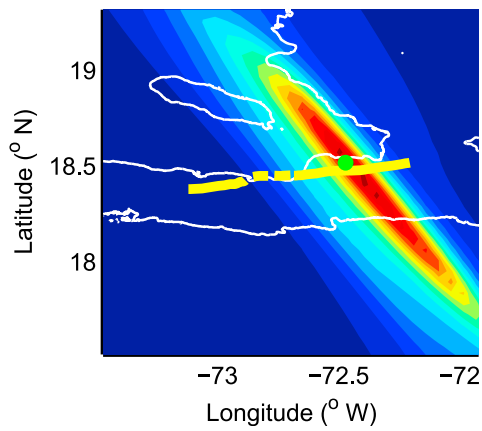

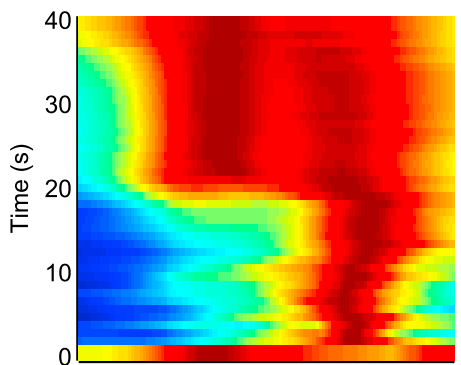

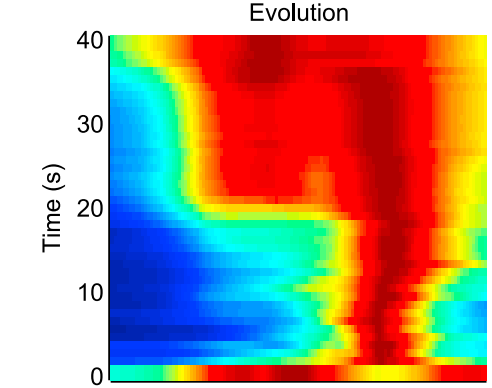

Evolution

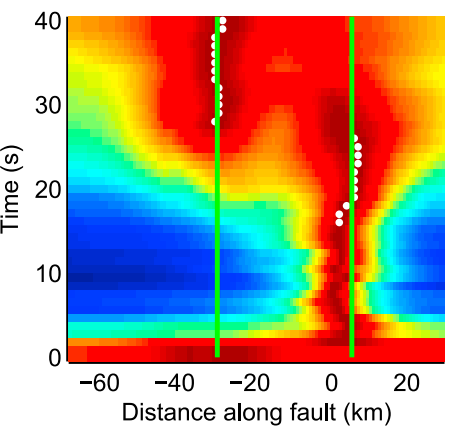

Figure 9. Array analysis of the Haiti event considering (a) cubic root stacking, (b) correlation stacking, and (c) MUSIC. The left two columns show backprojection images at $\mathrm{t}=15 \mathrm{~s}$ and $30 \mathrm{~s}$. The MUSIC analysis has higher resolution and can clearly separate two asperities. The blue line in Figure 9a (left) is the major axis of the array response pattern along which we project the array analysis onto the fault. The right column shows the projection on the fault as a function of final time of the sliding window. In Figure 9c (right), the peak locations of the two subevents are marked by white dots. For each subevent, the averaged location is denoted by the green line. The rest of the symbols are used in the same fashion as in Figure 8.

direction. Our analysis provides accurate source location only in the perpendicular direction, which is subparallel to the EPGF strike. We hence extract the maximum of the MUSIC pseudospectrum along lines parallel to the sourceto-array direction, then project these maxima onto the EPGF trace. Note that this aftershock has a slightly different strike $\left(\mathrm{N} 290^{\circ}\right)$ than the EPGF $\left(\mathrm{N} 255^{\circ}\right)$ but this difference is minor for this magnitude. Figure $8 \mathrm{c}$ shows this quantity as a function of epicentral distance along the EPGF strike and of final time of the sliding window. This result indicates that the aftershock is properly imaged as a compact source of $5 \mathrm{~km}$ size near its hypocenter. This distance could either be the dimension of the source [Wells and Coppersmith, 1994], or the spatial uncertainty of the source location.
In either case, it suggests little spatial smearing in our analysis at the $5 \mathrm{~km}$ scale and warrants imaging of the main shock, which is possibly composed of multiple subevents.

[19] Figure 9 shows the results of our application of MUSIC to the VNSN recordings of the 2010 Haiti main shock. We also applied two other popular array techniques, cubic root stack and correlation stack with the same stations set and frequency band, shown in Figures 9a and 9b, respectively. Although all these array analysis techniques unambiguously indicate two prominent subevents, our multitaper MUSIC algorithm provides the images with the sharpest contrast between the subevents and the adjacent areas, as expected from our synthetic tests. Note that the peak locations of the MUSIC imaging are off the fault trace, 
to the South, due to limited resolution along the sourceto-array direction at regional distance, which highlights the importance in regional array processing of a projection along the source-to-array direction onto the fault trace. The first subevent is located approximately $5.4 \mathrm{~km}$ east from the hypocenter. This distance is obtained by fitting a constant location to the peak location of the first event measured after the estimated location is stabilized $(\mathrm{t}=15 \mathrm{~s})$ and before the second subvevent becomes dominant $(t=27 \mathrm{~s})$. The second subevent is approximately $35.7 \mathrm{~km}$ further west $(30.3 \mathrm{~km}$ west from the hypocenter) based on the peak locations of the second suvevent measured after $\mathrm{t}=27 \mathrm{~s}$. This complexity is absent in the results of our analysis of the M5.9 aftershock (Figure 8) and hence is not due to path effects or other phases. The temporal evolution is better imaged by array processing at the peak frequency $(0.4 \mathrm{~Hz})$. In Figure $4 \mathrm{~b}$, bilateral propagation is observed starting around $\mathrm{t}=10 \mathrm{~s}$, when the last $10 \mathrm{~s}$ of the $30 \mathrm{~s}$ window contain the signal. The eastward front runs for about $10 \mathrm{~km}$ in about $3 \mathrm{~s}$. The westward front shows a weaker MUSIC pseudospectra but its propagation can be consistently tracked over a distance of $\sim 35 \mathrm{~km}$ and a duration of about $10 \mathrm{~s}$ (until $\mathrm{t} \approx 20 \mathrm{~s}$ ). The rupture speed of both fronts is similar and consistent with usual subshear rupture speeds, given the shear wave speed of $3.65 \mathrm{~km} / \mathrm{s}$ at $10 \mathrm{~km}$ depth in the Haiti region [Bassin et al., 2000]. These estimated subevent locations are consistent with the array analysis at the peak frequency of $0.4 \mathrm{~Hz}$ (Figure 4), although for the sake of robustness, the average over frequency band $0.2 \sim 0.7 \mathrm{~Hz}$ (Figure 9) is presented as our main result. The observed features are also compatible with the USArray source time functions and finite fault inversions described in section 5 .

\section{Comparison to Independent Observations}

[20] Our study is the first example of earthquake source imaging at regional distance with $P n$ waves for earthquakes of magnitude as low as 7. To build confidence in our results, we compare them here to other available observations. The complementarity between the different source analysis techniques provides an integrated view of the 2010 Haiti earthquake rupture process.

\subsection{Source Time Functions at USArray}

[21] The temporal separation between the two asperities is independently estimated from apparent source time functions obtained through deconvolution of teleseismic data by theoretical Green's functions (Figure 10) [Chu et al., 2009]. We selected USArray stations with epicentral distances greater than 30 degrees to avoid complexities of the $P$ waveform due to triplication in the upper mantle. We computed synthetic Green's function using the generalized ray theory [Helmberger, 1983], the IASPEI91 1D global velocity model [Kennett and Engdahl, 1991] with the upper $30 \mathrm{~km}$ adjusted to a 4 layer Haiti regional crust model [Bassin et al., 2000] and the CMT solution (www.globalcmt. org). The vertical component $P$ waveforms and synthetic Green's functions are filtered from 0.01 to $1 \mathrm{~Hz}$ and deconvolved in the time domain with the iterative technique of [Kikuchi and Kanamori, 1982] and with the nonnegative least squares algorithm [Lawson and Hanson, 1974]. Both deconvolution techniques yield consistent results. To estimate the temporal separation between the subevents and its uncertainty, we considered 1000 stacks of randomly selected subsets containing $90 \%$ of the USArray stations. We measured the delay between the two prominent peaks in the stacked apparent source time functions. We allow a $5 \mathrm{~s}$ range when estimating the timing of the second peak. Although some of the individual curves are noisy and bumpy, the bootstrapped stacked curve is smooth and robust. The estimated delays have a Gaussian distribution with mean $\mathrm{t} 1=5 \mathrm{~s}$ and standard deviation $0.02 \mathrm{~s}$ (Figure 10). We associate these to the two subevents found by our array analysis. The deconvolution analysis also indicates that the second subevent accounts for approximately one third of the total moment release, consistent with the multiple CMT solution of Nettles and Hjorleifsdottir [2010]. Their analysis also indicates that the second subevent has a thrust mechanism, in contrast to the near strikeslip mechanism of the first subevent. Nevertheless, at the azimuth of the USArray both mechanisms produce similar amplitudes and our choice to use the CMT solution to generate the Green's functions does not introduce a significant bias.

\subsection{Improved Finite Fault Model}

[22] To evaluate how the results of the backprojection and USArray analysis of the source time function relate to other data sets and integrate in the global description of the rupture, we perform a joint source inversion based on teleseismic body waves and the various geodetic data available.

[23] As detailed in previous studies [Calais et al., 2010; Hayes et al., 2010; Hashimoto et al., 2011], the campaign GPS measurements and InSAR data provide a very good coverage of the Leogane delta where the rupture started and indicate that the deformation in this area is best explained by a fault segment dipping NNW. In agreement with those studies, we choose a fault strike of $254^{\circ}$ and a dip angle of $55^{\circ}$. This orientation of the fault plane is also compatible with the alignment of aftershocks along a $75^{\circ} \mathrm{N}$ azimuth [Mercier de Lépinay et al., 2011]. InSAR fringes (ALOS ascending track 137) and field measurements of the coastal vertical uplift in the area near the town of Petit Goave [Hayes et al., 2010] suggest the earthquake also extended west and offshore of the Leogane delta. This hypothesis is supported by the aftershock catalog obtained from the HaitiOBS local network of terrestrial and ocean bottom seismic stations [Mercier de Lépinay et al., 2011]. In contrast with previous models, we do not cover this offshore area by simply extending the preferred Leogane fault geometry (i.e., dipping $\mathrm{NNW}$ ) to the west, but refine the model with a distinct second fault segment dipping $45^{\circ}$ to the NNE (strike $\mathrm{N} 275^{\circ}$ ). This NNW to NNE rotation in the fault strike is supported by the moment tensors of the aftershocks [Nettles and Hjorleifsdottir, 2010] and by the identification of bathymetric features with a similar orientation, such as the Trois Baies fault and the Transhaitian belt [Mercier de Lépinay et al., 2011].

[24] The location of the NEIC epicenter is incompatible with our first fault segment as it would imply a very superficial rupture initiation $(\sim 2 \mathrm{~km})$, and would not be compatible in term of depth: the NEIC depth is fixed to $13 \mathrm{~km}$ by their location program. Moving the hypocenter in the northeast direction, as suggested by the higher-resolution 


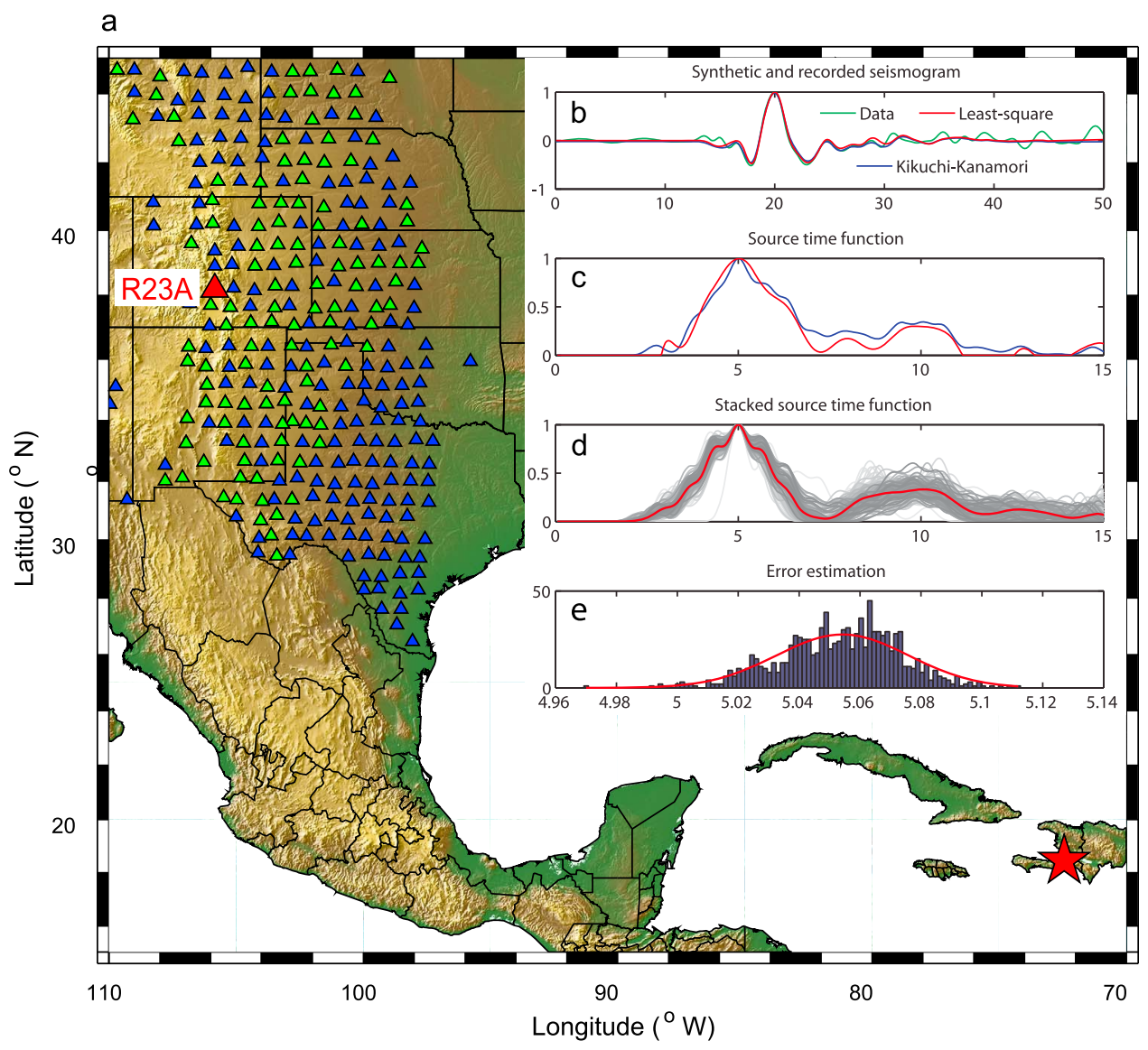

Figure 10. Source time function from USArray data. (a) The blue and green triangles show the USArray stations that recorded the Haiti event. The stations in green have epicentral distance greater than 30 degree and good signal-to-noise ratio, and are selected for deconvolution. The red star is the epicenter of the Haiti earthquake. The red triangle is station R23A. The insets show (b) the recorded and synthetic seismograms, (c) the source time function retrieved by nonnegative least squares (red) and Kikuchi-Kanamori deconvolution techniques (blue) at station R23A, and (d) source time functions (gray) from all selected USArray stations and the stacked source time function (red). (e) Histogram showing the delay between the two peaks from bootstrapping the stacked source time functions and the best fit Gaussian distribution (red curve).

Haiti-OBS aftershocks catalog (when compared to the NEIC catalog) [Mercier de Lépinay et al., 2011], brings the rupture initiation closer to the zone of high slip, as we would expect from the handpicked $P$ wave onset and assuming a standard rupture velocity $(\sim 3 \mathrm{~km} / \mathrm{s})$ at initiation (Figure S2). Note that using the hypocenter located by Mercier de Lépinay et al. [2011] $\left(72.499^{\circ} \mathrm{W}, 18.517^{\circ} \mathrm{N}, 12 \mathrm{~km}\right.$ deep) does not affect the array analysis other than by shifting the MUSIC subevents locations by a similar amount.

[25] The finite fault inversion is based on a Monte Carlotype algorithm [ $\mathrm{Ji}$ et al., 2002] and uses teleseismic data (21 $P$ waves and $13 S H$ waves bandpass filtered between 2 and 100 s), campaign GPS (data processing detailed by Calais et al. [2010]) and four InSAR images (data selection and processing detailed by Hayes et al. [2010]). We allow the rupture speed to vary from 3.0 to $3.6 \mathrm{~km} / \mathrm{s}$, that is, $\pm 0.3 \mathrm{~km} / \mathrm{s}$ around the rupture velocity inferred from the USArray analysis. We do not apply any minimization criteria on the seismic moment.

[26] We obtain a slip model composed of two high slip patches, a first one centered on the epicenter and a second one with peak slip amplitude $21 \mathrm{~km}$ further west, starting $6 \mathrm{~s}$ after the onset of rupture (Figure 11). The data misfit in our updated model (Table S1) is comparable to previous studies [Calais et al., 2010; Hayes et al., 2010; Hashimoto et al., 2011]. While the fit of the InSAR data is excellent (Figures S3 and S4), the fit of the GPS data is of moderate quality (Figure 11): this is mainly due to the large misfit at station DFRT which, despite having one of the largest measured displacements $(0.7 \mathrm{~m}$ measured in the center of the deformation area), cannot be adjusted either in azimuth or amplitude. At the location of station DFRT, ascending and descending InSAR tracks are too decorrelated to do a comparison of the 3D displacement. However, the smooth 3D pattern of deformation inferred from InSAR in the surrounding areas [Hayes et al., 2011] suggests that motion at DFRT is indeed affected by localized deformation. Calais et al. [2010], who also used InSAR and GPS data, could not fit properly station DRFT. The vertical deformation along the coast was measured using coral data [Hayes et al., 2010]. Since most of those measurements are within the area where InSAR coverage allows to estimate the vertical motion 


\section{Kinematic model (InSAR+GPS+teleseismic)}

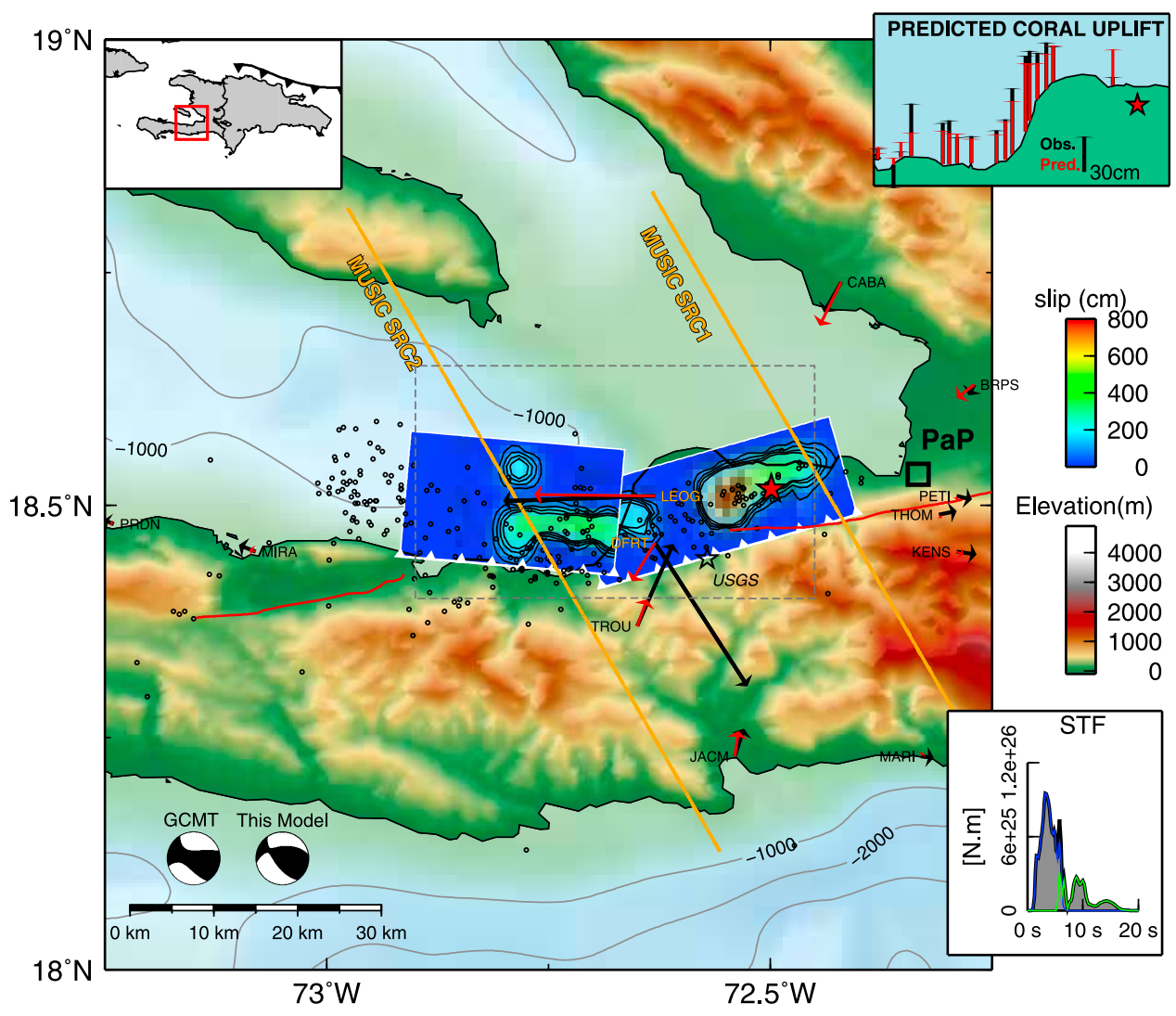

Figure 11. Improved joint finite fault inversion of the Haiti event. Surface projection of the slip distribution inferred from the joint inversion of teleseismic, GPS, and InSAR data. The black and red arrows represent the recorded and model-predicted campaign GPS vectors, respectively. The two orange lines mark the locations of the subevents identified by MUSIC backprojection assuming our refined main shock epicenter as reference (red star). The black empty star is the USGS epicenter. The small empty circles are the aftershock epicenters of the Haiti-OBS campaign. The three insets show the location of the study area (top left), the measured (black) and predicted (red) coastal uplift based on coral data [Hayes et al., 2010] (top right), and the inverted source time function (bottom right). The dashed line rectangle on the main map corresponds to spatial extent of the coastal uplift inset map. On the source time function plot, the blue and green curves show the contribution of the Leogane and offshore fault segments, respectively.

(overlap of ascending and descending tracks) we did not include them in the inversion and only made sure that they are compatible a posteriori. The compatibility is verified for all points (inset in Figure 11) except one subsidence measurement west of the surveyed area and the eastern most point. In the case of the subsidence point, the fact that this point moves down when the surrounding points move up suggests that it represents a local effect, perhaps a local slump similar to what is described by McHugh et al. [2011] and Mercier de Lépinay et al. [2011] in the offshore survey of this area. The easternmost surveyed point (inset in Figure 11) is inconsistent with the InSAR data [Hayes et al., 2010, Figure 2] and therefore cannot be fit properly. We note however that this area corresponds to the eastern end of the rupture where the uplift pattern decrease rapidly to zero (from +30 to $0 \mathrm{~cm}$ in less than $5 \mathrm{~km}$, Figure S5) and never goes below $-10 \mathrm{~cm}$. Thus, the predicted surface deformation is consistent with the observation of no vertical motion east of the rupture $(0$ to $-10 \mathrm{~cm}$ of subsidence is within the error bar of the coral measurements).

[27] Slip reaches a maximum of $10 \mathrm{~m}$ (Figure S6) at the center of the first patch ( $7 \mathrm{~m}$ for the second patch) which concentrates $2 / 3$ of the total moment $\left(310^{+19} \mathrm{~N} \mathrm{~m}\right.$ for the first patch, $1.510^{+19} \mathrm{~N} \mathrm{~m}$ for the second). This result is similar to our analysis of the USArray data. In term of bulk parameters, we also find that the moment tensor of our solution (Figure 11) and its seismic moment $\left(4.510^{+19} \mathrm{~N} \mathrm{~m}\right)$ are similar to the CMT analysis [Nettles and Hjorleifsdottir, 2010]. The teleseismic data bound the duration of the source time function to less than $15 \mathrm{~s}$ and indicate that the first patch of slip was more impulsive than the second and smaller slip episode. The oblique rake along the rupture is consistent with the transcompressional regime in this region [Mercier de Lépinay et al., 2011] but doesn't support the hypothesis of a fully partitioned fault system where the 
EPGF would absorb the entire strike-slip component [Dixon et al., 1998; Calais et al., 2002]

\section{Discussion}

\subsection{The Rupture Speed}

[28] The rupture speed can be reliably constrained by the apparent subevent delay of $t_{1}=5 \mathrm{~s}$ and by the spatial subevent separation of $21 \mathrm{~km}$ between the two subevents centroids provided by our geodetic-only slip inversion in Figure S7. Considering a bilateral rupture, the real intersubevent time delay is $t_{0}=t_{1}+\cos \theta\left(L_{w}-L_{e}\right) / c$, where $\theta$ is the angle between the fault strike and the source-toarray direction (40 degrees), $\mathrm{c}$ is the apparent $P$ wave speed (12 km/s at epicentral distance of 40 degrees), $\mathrm{L}_{\mathrm{w}}$ and $\mathrm{L}_{\mathrm{e}}$ are the distances of the centroid of the westward and eastward subevents, respectively $\left(\mathrm{L}_{\mathrm{w}}=21 \mathrm{~km}\right.$ and $\left.\mathrm{L}_{\mathrm{e}}=0 \mathrm{~km}\right)$. This yields a true intersubevent time of $6.3 \mathrm{~s}$. The implied rupture speed, $3.3 \mathrm{~km} / \mathrm{s}$, is within the usual subshear range. For reference the shear wave speed is $3.65 \mathrm{~km} / \mathrm{s}$ at $10 \mathrm{~km}$ depth in the Haiti region [Bassin et al., 2000]. Although our regional array backprojection analysis currently has large uncertainties on the rupture timing (see section 3.1), our backprojection result at the dominant frequency, $0.4 \mathrm{~Hz}$ (Figure $4 \mathrm{~b}$ ), is consistent with this subshear rupture speed.

\subsection{Spatial Complementarity Between High- and Low-Frequency Source Properties}

[29] The primary results from the array analysis, the finite fault inversion and the source time function analysis suggest that the rupture propagates bilaterally with primary westward rupture and minor eastward component, breaking two main slip patches. In the finite fault inversion, dominated by frequencies lower than $0.2 \mathrm{~Hz}$, the first asperity is located near the epicenter and the second one is $21 \mathrm{~km}$ west and contributes to one third of the total seismic moment. On the other hand, the higher-frequency radiators imaged by the array analysis $(0.2-0.7 \mathrm{~Hz})$ suggest a distance of $35 \mathrm{~km}$ between the two asperities.

[30] Since the backprojection provides subevents locations relative to the hypocenter, the choice of epicenter is essential in interpreting the result of the array processing. Assuming the epicenter given by NEIC, the subevent locations are consistent with the spatial pattern of the aftershocks (NEIC catalog), which cluster into two groups. The eastern group is close to the main shock epicenter and the second group is located 30 to $40 \mathrm{~km}$ west. If we assume the NEIC hypocenter, the western subevent is well beyond the high slip patches derived from the finite fault model, implying possible slip further west offshore, unconstrained by geodesy. However, if we take the hypocenter adjusted by Mercier de Lépinay et al. [2011] using local data instead of the NEIC location, the two HF subevents coincide with the terminal edges of the large slip areas. If we use the original NEIC hypocenter, the difference of the HF event and the peak slip zone is less obvious for the eastern asperity but still holds for the western asperity. This type of spatial complementarity between high- and low-frequency source properties was inferred for several other earthquakes, including the 1989 Loma Prieta earthquake, the 1993 Kushiro-Oki earthquake [Nakahara, 2008] and the 2011 Tohoku-Oki earthquake [Ide et al., 2011; Meng et al., 2011; Simons et al., 2011]. This complementarity can be interpreted as high-frequency radiation generated by the stopping phases, associated with abrupt rupture speed reduction at the edge of the slip area. This mechanism of high-frequency radiation was first described in circular crack models [Madariaga, 1977, 1983] and was explained for general rupture front geometries through isochrone theory [Bernard and Madariaga, 1984; Spudich and Frazer, 1984]. This interpretation is also consistent with the aftershock locations clustering at the regions of stress concentration at the edges of the coseismic rupture. Although the "stopping phase" interpretation is plausible for this particular earthquake, the generalization to other earthquakes is not warranted. Regardless of the mechanical origin of the high-frequency radiation, the backprojection analysis indicates its location. This is of practical importance for earthquake damage assessment. Note that the high-frequency radiation is absent at the western end of the first asperity, implying a smoother stopping or rupture transition without stopping between the two asperities.

\subsection{Extent of the Offshore Rupture}

[31] One aspect of the 2010 Haiti earthquake which still remains to be elucidated is the extent to which the rupture propagated offshore. Previous studies did infer offshore faulting [Calais et al., 2010; Hayes et al., 2010; Hashimoto et al., 2011; Mercier de Lépinay et al., 2011] but these models didn't use all the now available data sets to constrain the slip extent and/or the fault geometry onto which slip should be projected. Taking into account all these data, we investigate the possibility that the rupture extended further offshore than previously thought. In particular, observations in the offshore region are suggestive of rupture extending further west than previously published source models. Marine seismic reflection profiles indicate the existence of a large-scale active anticline associated with the Trois Baies fault and the Transhaitian belt [Mercier de Lépinay et al., 2011]. The aftershock locations derived from the HaitiOBS campaign are offset by about $20 \mathrm{~km}$ NE relative to the NEIC catalog locations [Mercier de Lépinay et al., 2011], implying that the western aftershock cluster is not onland but offshore. The Haiti-OBS catalog also confirms the existence of a cluster of aftershocks more than $30 \mathrm{~km}$ west of the epicenter, 10-20 km beyond the western end of coseismc slip of previous source models.

[32] While there is no direct offshore geodetic measurements to constrain the western end of the rupture, InSAR and GPS data cannot be properly explained by onland faulting alone. GPS station LEOG strongly points offshore and west of the Leogane delta (Figure 11) despite the existence of an asperity east of that point (this asperity is directly visible in the descending InSAR track 447). The dense InSAR fringes of acending track 137 (Figure S4) surround the coastline pointing to deformation in the center of the bay.

[33] In our kinematic source inversion based on teleseismic and geodetic data, slip is allowed to spread over more than $45 \mathrm{~km}$ west of the hypocenter (=maximum source duration $\times$ maximum rupture speed $=15 \times 3 \mathrm{~km}$ ). However, in the resulting model the slip remains confined to less than $22 \mathrm{~km}$ west of the epicenter. We obtained a similar slip distribution in a finite fault inversion based only on the static data sets, InSAR and GPS (Figures S7 and S8) without constraint on the seismic moment, with comparable fit to 
the data (Figures S9 and S10) and with a seismic moment $\left(5.010^{+19} \mathrm{~N} \mathrm{~m}\right)$ very close to the CMT solution $\left(4.710^{+19} \mathrm{~N} \mathrm{~m}\right)$. Moreover, the InSAR fringes along the coast (tracks A138a and A447d in Figure S10) tend to rotate slightly perpendicular to western end of our slip model, which suggests that there are no regions with larger slip further west.

[34] In summary, several arguments indicate that our preferred slip model did not miss any significant offshore deformation to the west. This result is consistent with the previously published models even though those models relied on different fault geometries. The spatial resolution of our regional backprojection is too coarse in the source-toarray direction (NNW-SSE) to provide an independent constraint on the distance between the coast and the second high-frequency source. However, the position of this second source along the cross-range direction (subparallel to the EPGF strike) is well constrained and is shown here to be consistent with the western end of offshore slip inferred from static deformation. This supports the idea that backprojection source imaging can identify the end tips of a rupture.

\subsection{Advantage of Regional Array Backprojection for Earthquake Source Studies}

[35] Our study of the 2010 Haiti earthquake demonstrates that backprojection of $P$ waves recorded at regional distances can reveal the location of high-frequency source radiation that are not resolvable by finite source inversions at teleseismic distance, which are now common practice. This new capability, improved by our analysis procedure combining multitaper and MUSIC techniques, allows to study the rupture of earthquakes with magnitude as low as 7 providing reliable spatial constraints. The approach requires that the approximate strike of the fault is known, but this information can usually be reliably extracted from the focal mechanism of the event. This implies that regional backprojection will be critical in the study of earthquakes when geodetic coverage is incomplete or local seismic networks are lacking, for instance in subduction zones. Moreover, the procedure can be automated for rapid, possibly real-time, earthquake analysis, combining the fault strike information from fast moment tensor inversions. In that sense, the VNSN alone has a great potential for the analysis of earthquake hazard for the whole Caribbean-North America plate boundary. The high-frequency aspects of the source process derived from array backprojection are particularly useful to estimate potential damage in regions where the vulnerable components of the building stock are dominated by low rise (short period) buildings. In a more global perspective, the statistical analysis of the last 120 years of earthquakes demonstrate that most of the devastating earthquakes occur in continental interiors on previously unmapped faults [England and Jackson, 2011]. Thus, with the ongoing development of regional seismic networks, many of those devastating earthquakes will still happen at regional distance from networks, and require the resolving power of regional backprojection.

\section{Conclusions}

[36] In this study, we developed a backprojection source imaging technique for body waves recorded by seismic arrays at regional distances ( $P n$ waves). The technique combines the Multiple Source Classification (MUSIC) method with multitaper cross-spectral estimation to achieve sharper source imaging than existing methods. This technique allowed us to extract key aspects of the rupture process of the 2010 Haiti earthquake from recordings by the Venezuela National Seismic Network (VNSN). In particular, it provides the locations of high-frequency source radiation. When integrated with independent studies based on teleseismic and geodetic data of this earthquake, our results indicate bilateral rupture at subshear speed, with a much longer rupture segment toward the West. Prominent highfrequency radiation originates from rupture arrest phases at the tip of the main slip areas. Additional rupture offshore is not supported by our analysis. Our results demonstrate how regional array studies can contribute to the characterization of seismic sources in the Caribbean region and elsewhere, particularly in offshore regions where local seismic network or geodetic data coverage are not available, with potential application for rapid earthquake response.

[37] Acknowledgments. This research was supported by NSF grant EAR-1015704, by the Gordon and Betty Moore Foundation, and by the Southern California Earthquake Center, which is funded by NSF Cooperative Agreement EAR-0106924 and USGS Cooperative Agreement 02HQAG0008. This paper is Caltech Tectonics Observatory contribution 196 and Caltech Seismolab contribution 10073

\section{References}

Bassin, C., G. Laske, and G. Masters (2000), The current limits of resolution for surface wave tomography in North America, Eos Trans. AGU, 81(48), Fall Meet. Suppl., Abstract S12A-03.

Bernard, P., and R. Madariaga (1984), High-frequency seismic radiation from a buried circular fault, Geophys. J. R. Astron. Soc., 78(1), 1-17, doi:10.1111/j.1365-246X.1984.tb06468.x.

Borcea, L., G. Papanicolaou, and C. Tsogka (2005), Interferometric array imaging in clutter, Inverse Probl., 21(4), 1419-1460, doi:10.1088/0266$5611 / 21 / 4 / 015$

Calais, E., Y. Mazabraud, B. M. de Lepinay, P. Mann, G. Mattioli, and P. Jansma (2002), Strain partitioning and fault slip rates in the northeastern Caribbean from GPS measurements, Geophys. Res. Lett., 29(18), 1856, doi:10.1029/2002GL015397.

Calais, E., A. Freed, G. Mattioli, F. Amelung, S. Jonsson, P. Jansma, S. H. Hong, T. Dixon, C. Prepetit, and R. Momplaisir (2010), Transpressional rupture of an unmapped fault during the 2010 Haiti earthquake, Nat. Geosci., 3(11), 794-799, doi:10.1038/ngeo992.

Chu, R., L. P. Zhu, and D. V. Helmberger (2009), Determination of earthquake focal depths and source time functions in central Asia using teleseismic $P$ waveforms, Geophys. Res. Lett., 36, L17317, doi:10.1029/ 2009GL039494

Dixon, T. H., F. Farina, C. DeMets, P. Jansma, P. Mann, and E. Calais (1998), Relative motion between the Caribbean and North American plates and related boundary zone deformation from a decade of GPS observations, J. Geophys. Res., 103(B7), 15,157-15,182, doi:10.1029/ 97JB03575.

England, P., and J. Jackson (2011), Uncharted seismic risk, Nat. Geosci., 4, 348-349, doi:10.1038/ngeo1168.

Fletcher, J. B., P. Spudich, and L. M. Baker (2006), Rupture propagation of the 2004 Parkfield, California, earthquake from observations at the UPSAR, Bull. Seismol. Soc. Am., 96, S129-S142, doi:10.1785/ 0120050812.

Goldstein, P., and R. J. Archuleta (1991), Deterministic frequencywavenumber methods and direct measurements of rupture propagation during earthquakes using a dense array: Theory and methods, J. Geophys. Res., 96(B4), 6173-6185, doi:10.1029/90JB02123.

Guilbert, J., J. Vergoz, E. Schissele, A. Roueff, and Y. Cansi (2005), Use of hydroacoustic and seismic arrays to observe rupture propagation and source extent of the $M_{w}=9.0$ Sumatra earthquake, Geophys. Res. Lett., 32, L15310, doi:10.1029/2005GL022966.

Hashimoto, M., Y. Fukushima, and Y. Fukahata (2011), Fan-delta uplift and mountain subsidence during the Haiti 2010 earthquake, Nat. Geosci., 4(4), 255-259, doi:10.1038/ngeo1115. 
Hayes, G. P., et al. (2010), Complex rupture during the 12 January 2010 Haiti earthquake, Nat. Geosci., 3(11), 800-805, doi:10.1038/ngeo977.

Helmberger, D. V. (1983), Theory and application of synthetic seismograms, in Earthquakes: Observation, Theory and Interpretation, pp. 174-222, Soc. Ital. di Fis, Bologna, Italy.

Ide, S., A. Baltay, and G. Beroza (2011), Shallow dynamic overshoot and energetic deep rupture in the $2011 M_{w} 9.0$ Tohoku-Oki earthquake, Science, 332, 1426-1429.

Ishii, M., P. M. Shearer, H. Houston, and J. E. Vidale (2005), Extent, duration and speed of the 2004 Sumatra-Andaman earthquake imaged by the Hi-Net array, Nature, 435(7044), 933-936, doi:10.1038/nature03675.

Ji, C., D. J. Wald, and D. V. Helmberger (2002), Source description of the 1999 Hector Mine, California, earthquake, part I: Wavelet domain inversion theory and resolution analysis, Bull. Seismol. Soc. Am., 92(4), 1192-1207, doi:10.1785/0120000916.

Kennett, B. L. N., and E. R. Engdahl (1991), Traveltimes for global earthquake location and phase identification, Geophys. J. Int., 105(2) 429-465, doi:10.1111/j.1365-246X.1991.tb06724.x.

Kikuchi, M., and H. Kanamori (1982), Inversion of complex body waves, Bull. Seismol. Soc. Am., 72(2), 491-506.

Krim, H., and M. Viberg (1996), Two decades of array signal processing research: The parametric approach, IEEE Signal Process Mag., 13(4), 67-94, doi:10.1109/79.526899.

Lawson, C. L., and R. J. Hanson (1974), Solving Least Squares Problems, Prentice Hall, Englewood Cliffs, N. J.

Madariaga, R. (1977), High-frequency radiation from crack (stress drop) models of earthquake faulting, Geophys. J. R. Astron. Soc., 51(3), 625-651, doi:10.1111/j.1365-246X.1977.tb04211.x.

Madariaga, R. (1983), High-frequency radiation from dynamic earthquake fault models, Ann. Geophys., 1(1), 17-23.

McHugh, C. M., et al. (2011), Offshore sedimentary effects of the 12 January 2010 Haiti earthquake, Geology, 39(8), 723-726, doi:10.1130/ G31815.1.

Mendoza, C. (2005), Earthquake source-parameter estimation using regional waveforms: Implications for tsunami alerting in the Caribbean, Geophys. Res. Lett., 32, L24314, doi:10.1029/2005GL024435.

Meng, L. S., A. Inbal, and J. P. Ampuero (2011), A window into the complexity of the dynamic rupture of the $2011 M_{w} 9$ Tohoku-Oki earthquake, Geophys. Res. Lett., 38, L00G07, doi:10.1029/2011GL048118.

Mercier de Lépinay, B., et al. (2011), The 2010 Haiti earthquake: A complex fault pattern constrained by seismologic and tectonic observations, Geophys. Res. Lett., 38, L22305, doi:10.1029/2011GL049799.

Nakahara, H. (2008), Seismogram envelope inversion for high-frequency seismic energy radiation from moderate-to-large earthquakes, $A d v$. Geophys., 50, 401-426, doi:10.1016/S0065-2687(08)00015-0.

Nettles, M., and V. Hjorleifsdottir (2010), Earthquake source parameters for the 2010 January Haiti main shock and aftershock sequence, Geophys. J. Int., 183(1), 375-380, doi:10.1111/j.1365-246X.2010.04732.x.

Prentice, C. S., P. Mann, A. J. Crone, R. D. Gold, K. W. Hudnut, R. W. Briggs, R. D. Koehler, and P. Jean (2010), Seismic hazard of the Enriquillo-Plantain Garden fault in Haiti inferred from palaeoseismology, Nat. Geosci., 3(11) 789-793, doi:10.1038/ngeo991.
Rost, S., and C. Thomas (2002), Array seismology: Methods and applications, Rev. Geophys., 40(3), 1008, doi:10.1029/2000RG000100.

Schmidt, R. O. (1986), Multiple emitter location and signal parameterestimation, IEEE Trans. Antennas Propag., 34(3), 276-280, doi:10.1109/ TAP.1986.1143830

Simons, M., et al. (2011), The 2011 magnitude 9.0 Tohoku-Oki earthquake: Mosaicking the megathrust from seconds to centuries, Science, 332(6036), 1421-1425, doi:10.1126/science.1206731.

Snoke, J. A. (2009), Traveltime tables for iasp91 and ak135, Seismol. Res. Lett., 80(2), 260-262, doi:10.1785/gssrl.80.2.260.

Spudich, P., and E. Cranswick (1984), Direct observation of rupture propagation during the 1979 Imperial Valley earthquake using a short baseline accelerometer array, Bull. Seismol. Soc. Am., 74(6), 2083-2114.

Spudich, P., and L. N. Frazer (1984), Use of ray theory to calculate highfrequency radiation from earthquake sources having spatially variable rupture velocity and stress drop, Bull. Seismol. Soc. Am., 74(6), 2061-2082.

Thomson, D. J. (1982), Spectrum estimation and harmonic-analysis, Proc. IEEE, 70(9), 1055-1096, doi:10.1109/PROC.1982.12433.

Tromp, J., D. Komatitsch, and Q. Y. Liu (2008), Spectral-element and adjoint methods in seismology, Commun. Comput. Phys., 3(1), 1-32.

Vallée, M., M. Landes, N. M. Shapiro, and Y. Klinger (2008), The 14 November 2001 Kokoxili (Tibet) earthquake: High-frequency seismic radiation originating from the transitions between sub-Rayleigh and supershear rupture velocity regimes, J. Geophys. Res., 113, B07305, doi:10.1029/2007JB005520.

Vandecar, J. C., and R. S. Crosson (1990), Determination of teleseismic relative phase arrival times using multi-channel cross-correlation and leastsquares, Bull. Seismol. Soc. Am., 80(1), 150-169.

Wei, S., Z. Zhan, Y. Luo, S. Ni, Y. Chen, and D. V. Helmberger (2009), Rapid regional centroid solutions, Eos Trans. AGU, 90(52), Fall Meet. Suppl., Abstract S13A-1734.

Wells, D. L., and K. J. Coppersmith (1994), New empirical relationships among magnitude, rupture length, rupture width, rupture area, and surface displacement, Bull. Seismol. Soc. Am., 84(4), 974-1002.

Zhu, L. P., and D. V. Helmberger (1996), Advancement in source estimation techniques using broadband regional seismograms, Bull. Seismol. Soc. Am., 86(5), 1634-1641.

Zhu, L. P., and L. A. Rivera (2002), A note on the dynamic and static displacements from a point source in multilayered media, Geophys. J. Int., 148(3), 619-627, doi:10.1046/j.1365-246X.2002.01610.x.

J.-P. Ampuero and L. Meng, Seismological Laboratory, California Institute of Technology, 1200 E. California Blvd., Pasadena, CA 91106, USA. (lsmeng@caltech.edu)

H. Rendon, Fundación Venezolana de Investigaciones Sismológicas, Avenida Mara, Caracas 76880, Venezuela.

A. Sladen, CNRS, Géoazur, University de Nice-Sophia Antipolis, Bât. 4 250 rue Albert Einstein, Les Lucioles 1, Sophia-Antipolis, F-06560 Valbonne, France. 